\title{
Inhibition of the SHP-1 activity by PKC- $\theta$ regulates NK cell activation threshold and cytotoxicity
}

Aviad Ben-Shmuel ${ }^{\# 1}$, Batel Sabag ${ }^{\# 1}$, Guy Biber ${ }^{1}$, Abhishek Puthenveetil ${ }^{1}$, Moria Levy ${ }^{1}$, Tammir Jubany $^{1}$, Noah Joseph ${ }^{1}$, Omri Matalon ${ }^{1}$, Jessica Kivelevitz ${ }^{1}$ and Mira Barda-Saad ${ }^{1 *}$

\# These authors contributed equally to this manuscript.

\section{Affiliations:}

${ }^{1}$ The Mina and Everard Goodman Faculty of Life Sciences, Bar-Ilan University, Ramat-Gan 5290002, Israel.

*To whom correspondence should be addressed: Prof. Mira Barda-Saad, The Mina and Everard Goodman Faculty of Life Sciences, Bar-Ilan University, Ramat-Gan 5290002, Israel.

Tel.: +972-3-5317311; E-mail: Mira.Barda-Saad@biu.ac.il 


\begin{abstract}
Natural Killer (NK) cells play a crucial role in immunity, killing virally infected and cancerous cells. The balance of signals initiated upon engagement of activating and inhibitory NK receptors with cognate ligands determines killing or tolerance. Nevertheless, the molecular mechanisms regulating rapid NK cell discrimination between healthy and malignant cells in a heterogeneous tissue environment are incompletely understood. The SHP-1 tyrosine phosphatase is the central negative NK cell regulator, which dephosphorylates key activating signaling proteins. Though the mechanism by which SHP-1 mediates NK cell inhibition has been partially elucidated, the pathways by which SHP-1 is itself regulated remain unclear. Here, we show that phosphorylation of SHP-1 in NK cells on the S591 residue by PKC- $\theta$ promotes the inhibited SHP-1 "folded" state. Silencing PKC- $\theta$ maintains SHP-1 in the active conformation, reduces NK cell activation and cytotoxicity, and promotes tumor progression in-vivo. This study reveals a molecular pathway that sustains the NK cell activation threshold through suppression of SHP-1 activity.
\end{abstract}




\section{Introduction}

Natural Killer (NK) cells are a class of lymphocytes that comprise a central component of the innate immune system. They patrol the body and kill virally transformed and cancerous cells. NK cell effector functions are carried out by the release of cytotoxic granules containing perforin and Granzyme-B, which induce target cell death(Topham et al., 2009)'(Pipkin et al., no date). Furthermore, NK cells produce cytokines and chemokines, such as IFN- $\gamma$, which activate the

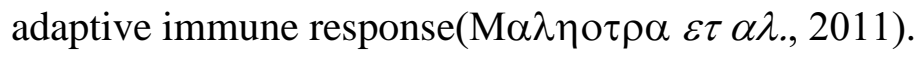

Activation or inhibition of NK function was shown to depend on the balance between signals derived from activating and inhibitory receptors on the NK cell surface(Lanier, 2005). Various motifs on the cytoplasmic tails of these receptors were shown to induce distinct downstream signaling cascades. These include immunoreceptor tyrosine-based activation motifs (ITAMs)

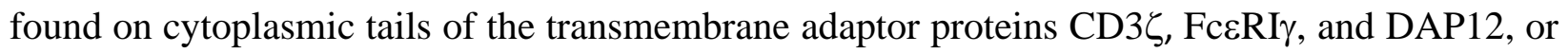
the YINM motif on the DAP10 adaptor, which associates with the NKG2D receptor(André et al., 2004). Another group of motifs includes the immunoreceptor tyrosine-based switch motifs (ITSMs) on the CD244 receptor(Lanier, 2003)'(Feng et al., 2005)'(Vyas et al., 2002b). Though NK cell receptors are well characterized, the molecular mechanisms downstream to receptor ligation, and how these are integrated to achieve the appropriate activation state, are incompletely understood.

Inhibitory NK cell receptors express a separate target sequence for signal suppression, consisting of immunoreceptor tyrosine-based inhibition motifs (ITIMs) expressed on the cytoplasmic tails(Long, 2008). The key receptors facilitating NK inhibition recognize Major Histocompatibility Class 1 (MHC-I) molecules expressed on the majority of cells in the body. These receptors include the Killer-cell Immunoglobulin-like Receptor (KIR) family in humans and primates, the Ly49 
family in mice, and NKG2A/CD94 receptors expressed in both primates and mice(Orr et al., 2010). NGK2A/CD94 were shown to have specificity for the Human Leukocyte Antigen (HLA) isoform E (HLA-E), whereas the KIR family of inhibitory receptors was shown to associate with HLA-C and HLA-B(Moretta et al., 1994)'(Wagtmann et al., 1995). Engagement of these receptors with their cognate ligands and phosphorylation of their ITIM motifs recruits the Src-homology 2domain (SH2)-containing protein tyrosine phosphatase (PTP), SHP-1. SHP-1 consequently dephosphorylates key proteins involved in the activating signaling pathway, thereby downregulating NK cell activation(Stebbins et al., 2003; Matalon et al., 2016). SHP-1 is comprised of a catalytic phosphatase domain near its $C^{\prime}$ terminus, two phospho-tyrosine binding $\mathrm{SH} 2$ domains towards its $\mathrm{N}^{\prime}$ terminus, and sites of tyrosine and serine phosphorylation at the end of its C'-terminal tail(Lorenz, 2009). In its auto-inhibited closed state, the SHP-1 N' SH2 domain associates with the catalytic domain, blocking access to its substrates.

Binding of SHP-1 SH2 domains to phosphorylated tyrosine residues on the ITIM of the inhibitory receptors induces a conformational alteration in SHP-1. This releases it from the inhibited state, and enables its catalytic activity, i.e. dephosphorylation of key signaling molecules and inhibition of NK cell function(Wang et al., 2011). SHP-1 substrates in NK cells include the guanine nucleotide exchange factor (GEF), VAV1(Stebbins, 2003), Phospholipase C gamma 1/2 (PLC $\gamma 1 / 2)$, and Linker for Activation of T-cells (LAT), recently identified by our group(Matalon, 2016).

Though SHP-1 function is critical for correct NK cell immune responses, the manner by which its catalytic activity is regulated remains unclear. Elucidating this mechanism is especially important, since NK cells engage target cells expressing both activating and inhibitory receptors, and SHP-1 recruitment to ITIMs decreases the activity of NK cell towards potential targets, despite expression 
of activating ligands. Therefore, upregulation of ligands for inhibitory NK receptors that express ITIMs by cancer cells, such as HLA-E and PD-L1, may repress NK cell activity through SHP-1 recruitment and activity(Carretero et al., 1998; Chemnitz et al., 2004). Identifying the factors that regulate SHP-1 activity may lead to a better understanding of how NK cell activity is accurately and rapidly tuned in tissues containing both healthy and transformed cells. We recently revealed that actin retrograde flow (ARF) induces a physical conformational change in the SHP-1 molecule to facilitate its activity(Matalon et al., 2018). However, key questions remain unresolved. SHP-1 was shown to localize to the lytic NK cell synapse (NKIS)(Vyas et al., 2002a), yet the mechanism by which its activity within the lytic synapse is regulated was not determined . Furthermore, it is not clear how termination of SHP-1 activity occurs after NK cells are successfully inhibited, thereby enabling NK cells to function in subsequent interactions with activating target cells.

Thus, since SHP-1 is a critical checkpoint molecule in NK cells and regulates the NK cell activation threshold, it is of great interest to understand the underlying mechanisms that control its catalytic activity during the NK cell response.

Here, we demonstrate that in NK cells, SHP-1 is heavily phosphorylated on the serine 591 residue (S591) via PKC- $\theta$ (and hence dormant) during activating but not inhibitory responses, within the first 5 minutes of NK cell activation. This phosphorylation is dynamic, and increases along the progression of the inhibitory NKIS, while slightly decreasing during progression of the activating NKIS. SHP-1 phosphorylation dynamics were also closely correlated with changes in SHP-1 catalytic conformations. Blocking PKC- $\theta$-mediated phosphorylation of SHP-1 restored SHP-1 activity and inhibited NK cell activation. Furthermore, NK cells bearing a phosphor-mimetic point mutation that suppresses SHP-1 activity 1 at the serine 591 residue were highly activated. Finally, knockout of SHP-1 in NK cells rescued PKC- $\theta$ silencing and promoted tumor clearance in-vivo. 
The PKC- $\theta$-mediated regulation of SHP-1 potentially serves to maintain and prime NK cellsin a complex cellular environment consisting of both healthy and malignant cells, requiring finely tuned localized NK cell activity.

\section{Results}

SHP-1 S591 phosphorylation in NK cells is a dynamic process, differentially regulated during inhibitory and activating interactions

It remains unclear how SHP-1 activity is regulated throughout the duration of the NK cell response, and how this regulation is maintained in different states, i.e. during NK cell activation and inhibition. Furthermore, SHP-1 is recruited to both cytolytic as well as non-cytolytic NK synapses, demonstrating that different modes of regulation are needed to ensure proper NK cell responses(Vyas et al., 2001; Vyas, 2002a). Phosphorylation of SHP-1 was previously shown in different cellular systems(Li et al., 1995; Jones et al., 2004; Liu et al., 2007). The outcome of these molecular processes, however, demonstrated contradictory results, and molecular regulation of SHP-1 in NK cells has not been fully addressed. We recently employed a mutant YTS-2DL1 knock-in line expressing the SHP-1 phosphor-mimetic serine to aspartic acid residue substitution (SHP-1 S591D), which exhibits increased anti-tumor NK function relative to WT SHP-1expressing YTS cells(Ben-Shmuel et al., 2020). To dissect the possible effect of SHP-1 phosphorylation on NK cell function, physiological activating and inhibiting interactions were induced with 721.221 target cells, and S591 phosphorylation patterns were examined in YTS2DL1 cells and isolated primary NK KIR2DL1 ${ }^{+}$cells (pNK-2DL1) from healthy human donors. We conducted functional assays as previously described(Matalon, 2016, 2018) by incubating YTS2DL1 or primary NK cells (pNKs cells) isolated from PBMCs of healthy donors expressing KIR2DL1+ (referred to as pNK KIR2DL1) with 721.221 target cells either expressing the 
KIR2DL1 cognate ligand, HLA Cw4 (721-Cw4, which inhibits NK activity), or an irrelevant HLA Cw7 ligand (721-Cw7 or 721- HLA negative cells(Münz et al., 1997), which promote NK cell activation). Cell lysates were immunoblotted with anti-pSHP-1 S591 antibody. Our data revealed different SHP-1 phosphorylation profiles during NK cell inhibition and activation after 5 minutes of incubation (Fig. 1A). High S591 phosphorylation levels could be seen during activating interactions $(3.06 \pm 0.31, P=0.0104)$, whereas lower SHP-1 S591 phosphorylation was observed during induced inhibitory interactions. The same pattern was observed during incubation of pNK2DL1 cells with activating 721-HLA negative cells or with inhibiting 721-Cw4 targets cells $(2.51 \pm 0.19, P=0.006$, Fig. 1B). The formation of the immunological synapse (IS) is highly dynamic, involving movement, activation, and termination of signaling complexes(Burroughs et al., 2002). Therefore, we wished to analyze the change in SHP-1 S591 phosphorylation over time. YTS-2DL1 or pNK-2DL1 cells were incubated with activating or inhibiting 721.221 targets for 5, 10, 15 and 20 minutes. Strikingly, we found that pS591 on SHP-1 was dramatically altered during formation of the inhibitory NK cell synapse, showing almost no initial phosphorylation after 5 minutes of incubation, and displaying high phosphorylation by 20 minutes. Activating NK cell interactions, however, displayed higher SHP-1 S591 phosphorylation during the first 5 minutes of activation, remaining relatively stable, with a slight (non-significant) reduction after 20 minutes of activation (Fig. 1C and Fig 1-Fig. supplement 1). Collectively these results suggest that SHP-1 S591 phosphorylation may play a role during NK cell activation, and during late inhibitory interactions. This mechanism may attenuate SHP-1 functionality in order to enable NK cell activation within these time frames. 


\section{Fig. 1}

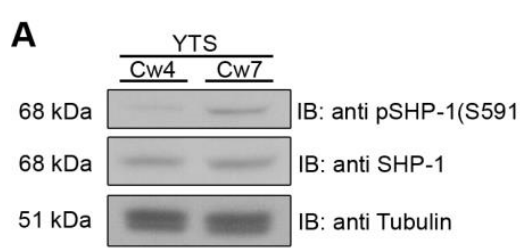

C
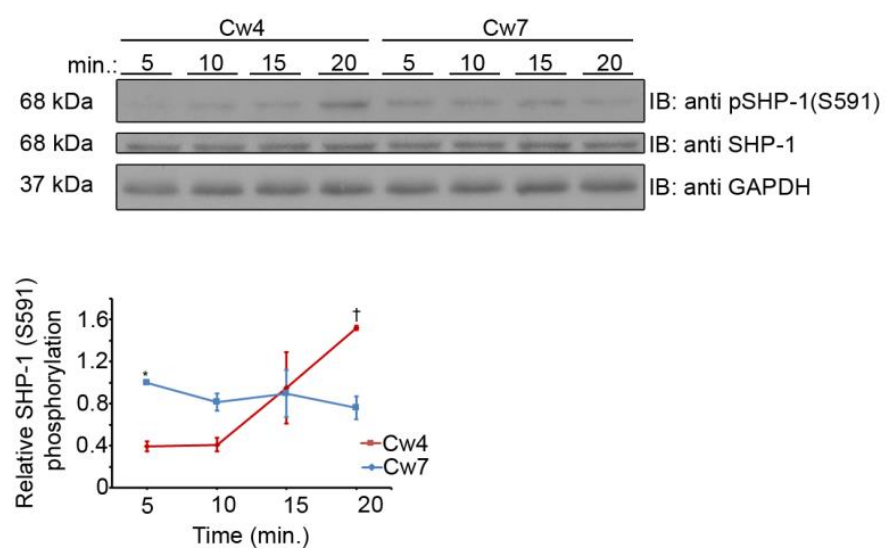
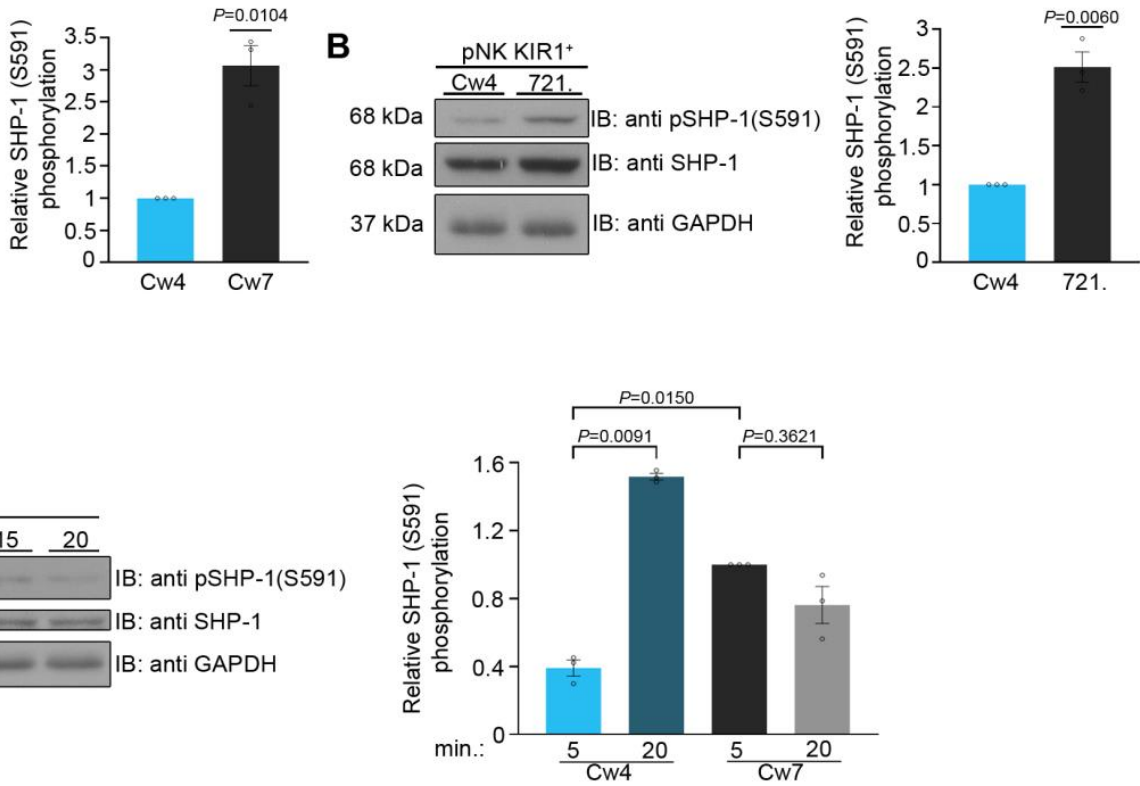

Fig. 1. Phosphorylation kinetics of SHP-1 S591 during activating and inhibitory NK cell interactions. (A) YTS2DL1 NK cells were incubated with either inhibitory 721-Cw4 HLA or 721-Cw7 HLA target cells at $37^{\circ} \mathrm{C}$ for 5 minutes, and then lysed. Lysates were separated on SDS page and immunoblotted with anti-pSHP-1 S591 antibody. SHP-1 S591 phosphorylation levels were measured by densitometric analysis, relative to $\square$-Tubulin loading control using ImageJ. Samples were normalized to the YTS-2DL1 sample incubated with 721-Cw4 target after 5 minutes of activation ( $P=0.0104$, quantification on the right showing the average of 3 independent experiments). (B) pNK-2DL1 cells were incubated with either 721 -Cw4 HLA or 721 -HLA negative target cells at $37^{\circ} \mathrm{C}$ for 5 minutes. pSHP-1 S591 levels were determined as in (a) $(P=0.0060$, quantification on the right showing the average of 3 independent experiments). (C) YTS-2DL1 cells were incubated with target cells as described in (a), for four different time points, as indicated. pSHP-1 S591 levels were quantitated as in (a). Statistical significance between Cw4 and Cw7 after 5 minutes of activation $(P=0.015)$, statistical significance between $\mathrm{Cw} 4$ at 5 minutes versus 20 minutes $(P=0.0091)$. pSHP-1 S591 levels of YTS-2DL1 cells incubated with targets for 5 and 20 minutes are shown in the bar graph (quantification showing the average of 3 independent experiments). Data are shown as mean \pm SEM. One sample $t-$ tests (A, B) or one-way ANOVA with Tukey test (C) were used to calculate $\mathrm{p}$ values

\section{Figure 1-source data 1: Representative blots}

Figure 1-source data 2 and and Figure 1-figure supplement 1- source data 1: Numerical data for all graphical presentation. 


\section{SHP-1 conformational kinetics parallel S591 phosphorylation patterns}

To elucidate whether SHP-1 phosphorylation on the S591 residue complements SHP-1 conformation and activation status, a SHP-1 Förster resonance energy transfer (FRET) bio- sensor construct was cloned into YTS-2DL1 cells as we previously described(Matalon, 2018). The FRET sensor was constructed with SHP-1 tagged on the N' and C' termini with YFP and CFP, respectively (YFP-SHP-1-CFP). It is known that SHP-1 activation status is correlated with its conformation(Poole et al., 2005; Wang, 2011). In the closed conformation the N' SH2 domain masks the catalytic domain rendering the enzyme inactive, whereas when the catalytic domain is free of the N' SH2 domain, the protein remains in an open active conformation(Wang, 2011). Hence, an inactive SHP-1 protein provides high FRET efficiency due to YFP and CFP proximity, and an active SHP-1 protein demonstrates low FRET efficiency as SHP-1 is in an open conformation, distancing the two reporter proteins. With this construct, we could image the dynamic activation and inhibition status of SHP-1 throughout the lifetime of the NKIS as previously reported(Matalon, 2018). YTS-2DL1 cells were transfected with the YFP-SHP-1-CFP FRET sensor construct and incubated with inhibiting 721-Cw4 or activating 721-Cw7 cells stably expressing mCherry in order to distinguish NK and target cells. FRET efficiency was measured using high resolution microscopy, as previously described(Barda-Saad et al., 2005; Pauker et al., 2012; Fried et al., 2014). In this set of experiments, we chose to focus on very early (5 minutes) and late (20 minutes) stages of NK cell: target cell interaction, as they showed the largest change in SHP-1 S591 phosphorylation (Fig. 1 and Fig.1- Fig. supplement 1). FRET measurements demonstrated patterns similar to SHP-1 S591 phosphorylation profiles; during initial inhibitory NK:721-Cw4 interactions (5 minutes), SHP-1 in NK cells displayed low synaptic FRET efficiency, indicating an open and active state $(8.62 \% \pm 1.8)$, shifting to high FRET efficiency after 20 minutes of synapse maturation $(15.13 \% \pm 1.9, P=0.0300$; Fig. 2 A\&B top two panels), indicating 
a closed and inhibited state. During activating interactions, however, SHP-1 in NK cells displayed highest synaptic FRET efficiency after 5 minutes $(18.45 \% \pm 1.9, P=0.0003$ comparing 5 minutes of activation to inhibition), indicating a closed and inhibited state, while after 20 minutes of activation, a decrease was observed in SHP-1 FRET efficiency to similar levels as NK:721-Cw4 interactions after 5 minutes $(8.15 \% \pm 1.9, P=0.006$; Fig. 2A\&B bottom two panels), indicating an open and active SHP-1 conformation(Matalon, 2018). These data demonstrate that SHP-1 conformation, and accordingly, its activation status, changes differentially during activating and inhibiting interactions as the NKIS matures, correlating with S591 phosphorylation patterns. Our results suggest that SHP-1 conformation and catalytic activation are regulated in a temporal manner at both the activating and inhibitory NKIS, and suggest a possible role for SHP-1 S591 phosphorylation on SHP-1 activity in NK cells. 


\section{Fig. 2}

\section{A}
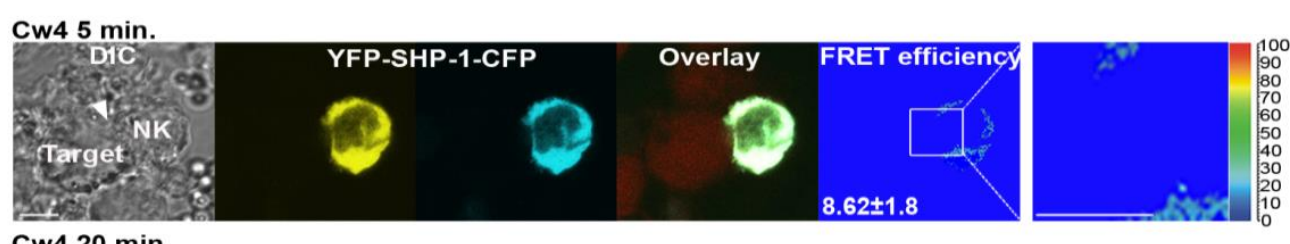

Cw4 20 min.
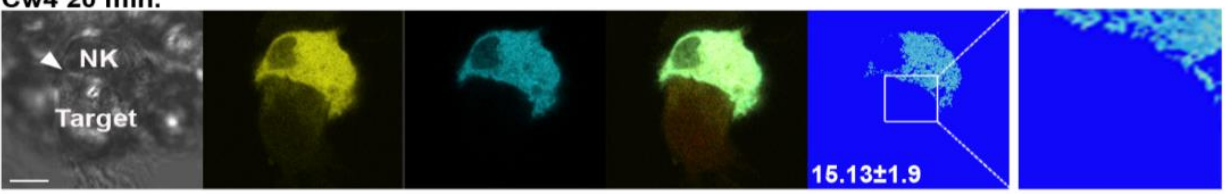

Cw7 $5 \mathrm{~min}$.
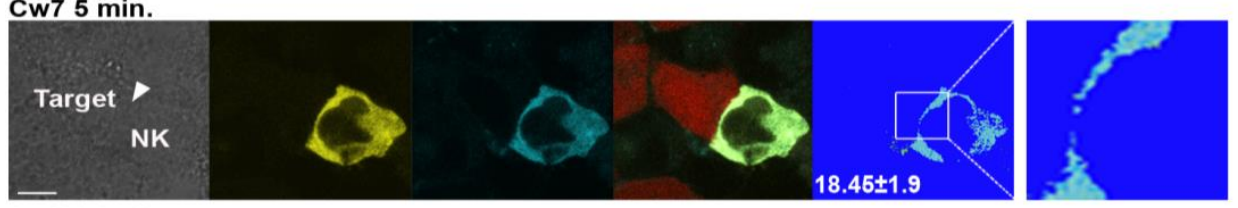

Cw7 20 min.
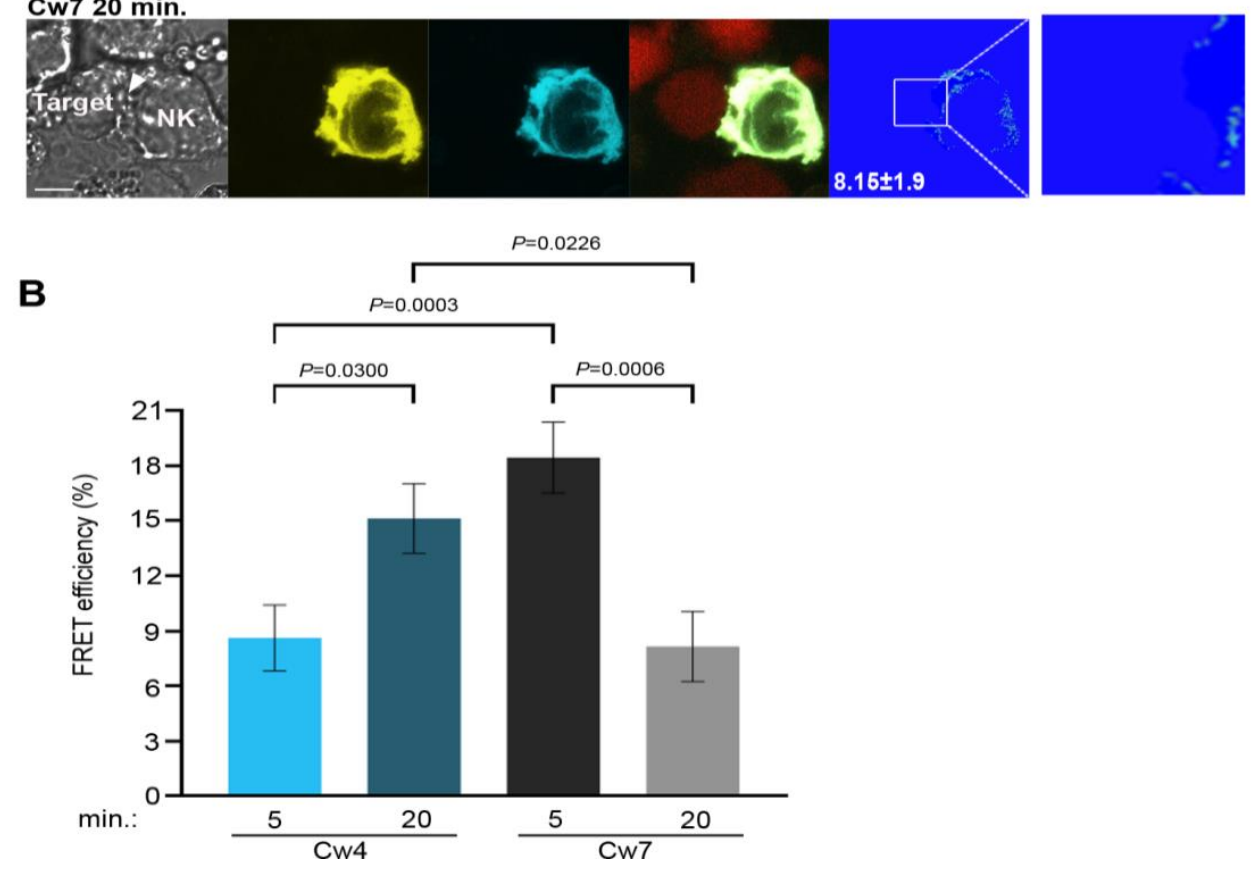

Fig. 2. SHP-1 conformational dynamics reflect $\mathbf{S 5 9 1}$ phosphorylation during activating and inhibitory NK cell interactions. (A) YTS-2DL1 YFP-SHP-1-CFP cells were incubated over slides pre-seeded with 721-Cw4 (top panels) or $\mathrm{Cw} 7$ (bottom panels) target cells expressing mCherry. The cells were incubated for 5 or 20 minutes at $37^{\circ} \mathrm{C}$ to enable conjugate formation, and fixed. FRET analysis was performed as indicated. (B) Graph summarizing FRET efficiency following 5 or 20 minute activation with Cw4 or Cw7 target cells. For Cw4, 5 and 20 minutes activation, $\mathrm{n}=72$ and 62 cell conjugates analyzed, respectively. For $\mathrm{Cw} 7,5$ and 20 minutes activation, $\mathrm{n}=73$ and 47 cell conjugates analyzed from three independent experiments, respectively. Data are shown as mean \pm SEM. Two-way ANOVA with Tukey test (B) were used to calculate $\mathrm{p}$ values

Figure 2-source data 1: Numerical data for the graphical presentation. 


\section{pSHP-1 distinguishes between NK cell activating and inhibiting synapses, and correlates}

\section{with PKC- $\theta$ accumulation at the NKIS}

In transformed tissues, NK cells interact with both susceptible targets and bystander cells which may both influence NK cell function(Zhou et al., 2017). NK cells are capable of serial cytotoxicity, and rapidly engage with and detach from these different targets(Choi et al., 2013; Forslund et al., 2015; Guldevall et al., 2016). It was recently demonstrated that NKIS maintenance is highly regulated, and signaling events which lead to NK cell attachment to new target cells accelerate the detachment from previous targets(Netter et al., 2017; Srpan et al., 2018). Furthermore, highly regulated lytic granule convergence to the MTOC is crucial for NK cells to avoid bystander cell killing(Hsu et al., 2016). Thus, it is evident that controlled and coordinated signaling events are critical for NK cell target identification and subsequent precise function.

We hypothesized that SHP-1 S591 phosphorylation may thus enable rapid discrimination by NK cells between healthy and malignant targets, facilitating controlled and sequential killing in a heterogeneous environment. To examine whether SHP-1 phosphorylation in NK cells is coordinately directed when NK cells are challenged simultaneously with activating and inhibitory signals, pNK-2DL1 cells were concurrently incubated with both activating K562-CFP and inhibiting 721-Cw4-mCherry stably labelled cells. Synapse intensity of pSHP-1 S591 was assessed in NK cells that were found forming simultaneous dual synapses with both activating and inhibiting cells. Strikingly, NK cells were able to rapidly distinguish between activating and inhibitory targets cells as measured by higher pSHP-1 S591 levels that were localized to synapses with K562, versus 721-Cw4 cells (Fig. 3A, $P=0.0074$ ). Hence SHP-1 S591 phosphorylation is a regulated and directed event and may allow NK cells to locally regulate SHP-1 phosphorylation to enable the maintenance of multiple local activation states in a single cell. 
We next aimed to identify the serine kinase implicated in SHP-1 S591 phosphorylation. PKC- $\theta$ is expressed predominantly in hematopoietic and muscle cells(Osada et al., 1992; Baier et al., 1993), and was shown to play multiple roles in T-cell activation(Hayashi et al., 2007). In human NK cells, the role and molecular pathways of $\mathrm{PKC}-\theta$ are incompletely defined. $\mathrm{PKC}-\theta$ was suggested to participate in murine NK cell activity(Tassi et al., 2008; Aguiló et al., 2009; Anel, Juan I Aguiló, et al., 2012; Merino et al., 2012), however the mechanism by which it exerts this function remains unclear. It was shown that TNF- $\alpha$ and IFN- $\gamma$ secretion is defective in PKC- $\theta^{-/-}$mice(Page et al., 2008), and this can contribute to defective recruitment of effector cells to the site of tumor development. In a different study(Tassi, 2008), no effect of PKC- $\theta$ deficiency was observed on IFN- $\gamma$ secretion induced by IL-12, IL-18, or a combination of both cytokines. Therefore, it is not clear how PKC- $\theta$ is involved in the regulation of NK cell signaling cascades, and if its activity impacts human NK cell function.

Early reports by Vyas et al showed that PKC- $\theta$ localizes to the cytolytic NK synapse during early activation, i.e. following 5 and 10 minutes of activating target cell conjugation, and relatively low PKC- $\theta$ polarization is observed following 10 minutes of non-cytolytic NK: target cell conjugates(Vyas, 2002a). This PKC- $\theta$ localization was similar to the localization of SHP-1 at the NKIS. Thus, we next studied PKC- $\theta$ dynamics in NK cell inhibitory synapses, and how these compare to PKC- $\theta$ localization during NK cell activation. Moreover, since PKC- $\theta$ plays a role in activation of different hematopoietic cells(Baier, 1993; Hayashi, 2007) and induces SHP-1 S591 phosphorylation during T-cell activation(Liu, 2007), we tested its possible interplay with SHP-1 in NK cells. YTS-2DL1 NK cells were incubated with mCherry labeled 721.221 target cells for either 5 (early) or 20 (late) minutes (Fig. 3B). PKC- $\theta$ localization appeared dispersed at the early inhibitory NKIS and accumulated at the synapse after 20 minutes $(P=0.0036)$. These dynamics 
were similar to SHP-1 S591 phosphorylation patterns. Furthermore, we observed PKC- $\theta$ accumulation at the activating NKIS at the initial time point, which did not significantly decrease after 20 minutes (Fig. 3 and Fig. 3-Fig. supplement 1A $P=0.5068$ ). This suggested that PKC- $\theta$ may play a role in regulating late inhibitory and early activating signaling pathways via SHP-1 regulation.

Next, we examined whether an interaction between PKC- $\theta$ and SHP-1 occurs in NK cells, and followed its dynamics during activation versus inhibition. To determine whether endogenous SHP1 binds PKC- $\theta$, YTS-2DL1 were incubated with 721.221 target cells for different time periods. Cell lysates were prepared, and immunoprecipitates (IPs) of SHP-1 were probed with anti- PKC$\theta$ antibody. A clear elevation in the interaction between SHP-1 and PKC- $\theta$ was detected during NK cell inhibition after 20 minutes, as opposed to a relatively constant association during NK cell activation (Fig.3-Fig. supplement 1B). Together, these data suggest that PKC- $\theta$ plays a role in human NK cell activation, and possibly in late (20 min) NK cell inhibition, potentially through SHP-1 regulation at the late inhibitory NKIS, and throughout the lifetime of the activating NKIS (5-20 minutes). 


\section{Fig. 3}

A

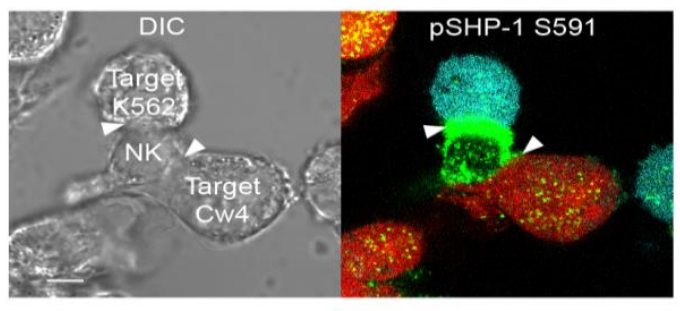

B
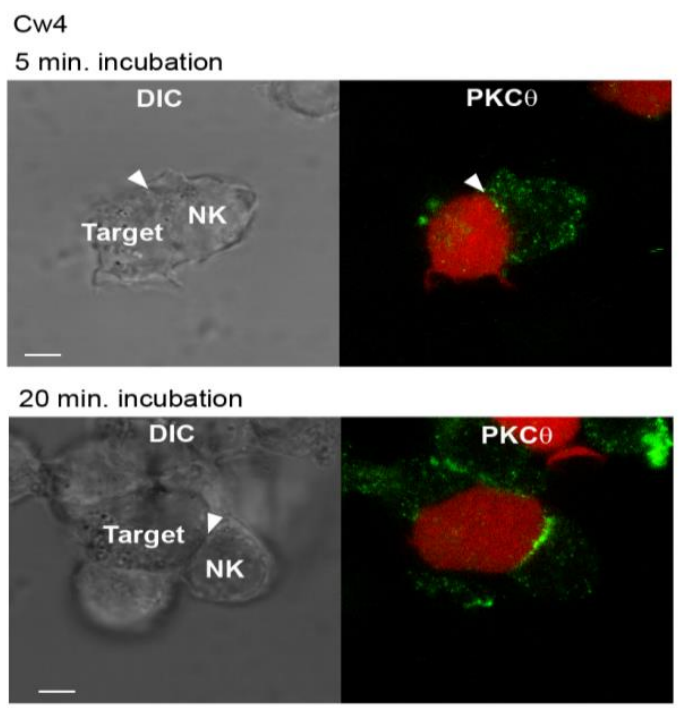
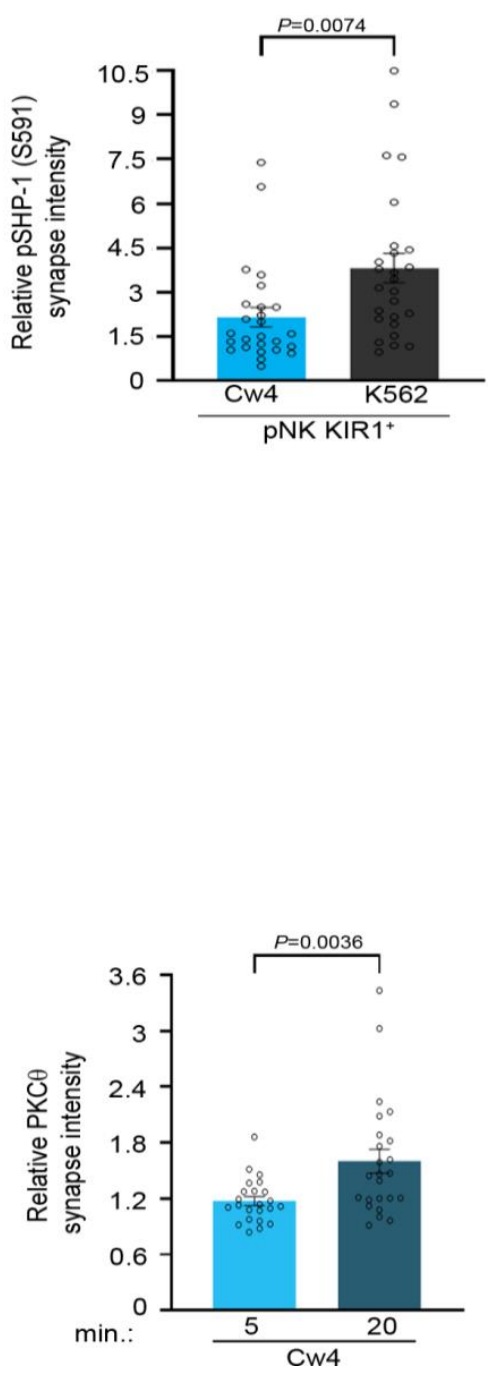

Fig. 3. Phosphorylation of SHP-1 S591 occurs at the activating NKIS during simultaneous activating and inhibitory synapse formation, in parallel to PKC- $\boldsymbol{\theta}$ accumulation. (A) pNK-2DL1 cells were incubated over slides pre-seeded with 721-Cw4 and K562 cells expressing mCherry or CFP, respectively. The cells were incubated for 5 minutes at $37^{\circ} \mathrm{C}$ to enable conjugate formation, and were fixed. pSHP-1 S591 was labeled with primary rabbit anti pSHP-1 S591 antibody, and secondary anti-rabbit 488 antibody. Synapse intensity was quantified in NK cells relative to each cell in multiple NK cell synapses with two different targets $(P=0.007$, quantification on the right of triple cell conjugates collected, $\mathrm{n}=26$ ). (B) YTS-2DL1 cells were incubated over slides pre-seeded with 721-Cw4 target cells expressing mCherry. The cells were incubated for 5 or 20 minutes at $37^{\circ} \mathrm{C}$ to enable conjugate formation, and were fixed. PKC- $\theta$ was subsequently labeled with primary goat anti PKC- $\theta$ antibody, and secondary anti-goat 488 antibody. (C) Graph summarizing PKC- $\theta$ accumulation at the NKIS at two activation times. Analysis was conducted comparing PKC- $\theta$ intensity at the NKIS relative to the rest of the NK cell. For Cw4 5 and 20 minute activation, $n=24$ cell conjugates were analyzed from three independent experiments. Data are shown as mean \pm SEM. One sample ttests $(\mathrm{A}, \mathrm{B})$ were used to calculate $\mathrm{p}$ values

Figure 3-source data 1 and Figure 3-Figure supplement 1-source data 2: Numerical data for all graphical presentation. 
Figure 3-Figure supplement 1-source data 1: Representative blots

\section{SHP-1 phosphorylation on S591 is facilitated through PKC- $\theta$}

In order to determine whether SHP-1 S591 phosphorylation is mediated through $\mathrm{PKC}-\theta$ in NK cells, a specific siRNA gene silencing approach was utilized in YTS-2DL1 and pNK-2DL1 cells. Cells were gene silenced for PKC $-\theta$ and incubated with 721.221 target cells (Fig. 4). Significant silencing efficiency was obtained in all experiments $(P=0.001$ and $P=0.0135$ for YTS and pNK2DL1 cells, respectively) relative to cells transfected with non-specific (NS) siRNA control (Fig. 4A\&Fig4 -Fig. supplement 1).

Next, SHP-1 S591 phosphorylation levels were examined in YTS-2DL1 and pNK-2DL1 cells that were treated with NS siRNA vs. PKC- $\theta$ siRNA, and incubated with 721-Cw7 or 721-HLA negative target cells, in order to elucidate the role of PKC- $\theta$ on SHP-1 S591 phosphorylation during stimulation. Though S591 phosphorylation was not completely eliminated, a reduction in SHP-1 S591 phosphorylation levels could be seen in YTS-2DL1 or pNK-2DL1 treated with PKC $-\theta$ siRNA as opposed to NS siRNA (by 2.5 fold $\pm 0.03, P=0.0072$; by 1.7 fold \pm 0.07 , $P=0.0113$, respectively) (Fig. 4B, C). Together, these data demonstrate PKC $-\theta$ is implicated in SHP-1 S591 phosphorylation in NK cells. 


\section{Fig. 4}

A
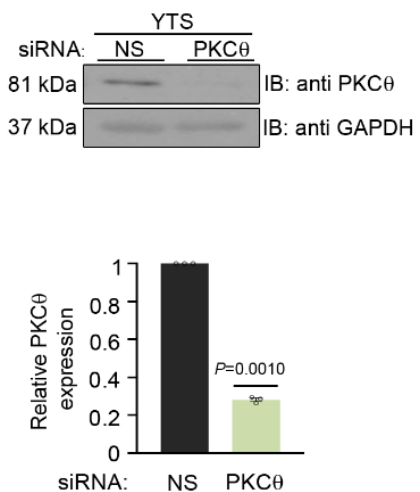

B
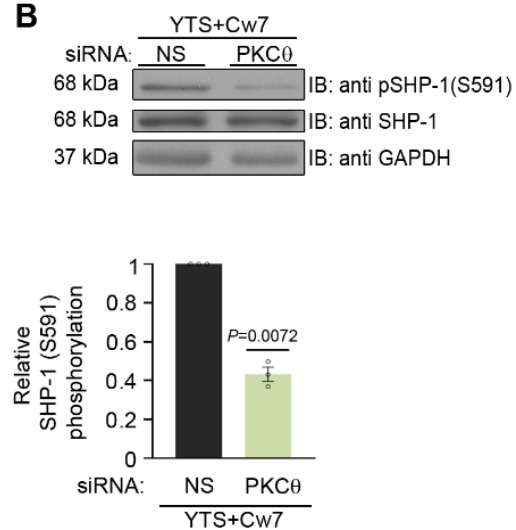

C
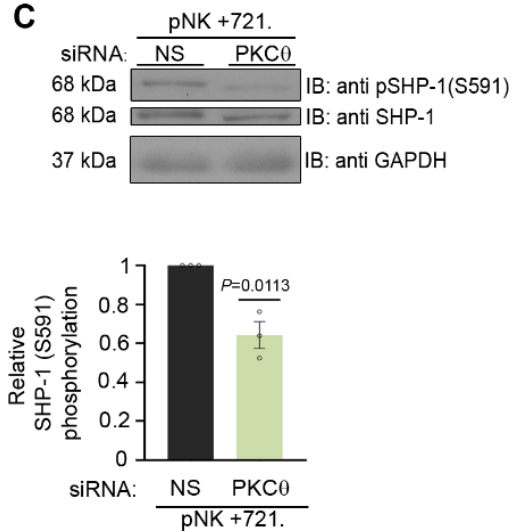

Fig. 4. SHP-1 phosphorylation is mediated through PKC- $\theta$. (A) NK cells were isolated and treated with either non-specific (control) (N.S) or PKC- $\theta$ siRNA, lysed, separated on SDS PAGE, and immunoblotted with anti- PKC- $\theta$ antibody. PKC- $\theta$ levels were measured by densitometric analysis, relative to the GAPDH loading control using ImageJ. Samples were normalized to the sample treated with N.S siRNA $(P=0.001$, quantification on the bottom showing average of 3 independent experiments). (B) YTS-2DL1 treated with either NS or PKC- $\theta$ siRNA were incubated with 721 - HLA target cells at $37^{\circ} \mathrm{C}$ for 5 minutes, and cells were subsequently lysed. Lysates were separated on SDS page transferred to a nitrocellulose membrane, and immunoblotted with anti-pSHP-1 S591 antibody. SHP-1 S591 phosphorylation levels were measured by densitometric analysis, relative to the GAPDH loading control using ImageJ. Samples were normalized to the YTS-2DL1 sample treated with non-specific siRNA and incubated with 721Cw7 target $(P=0.0072$, quantification on the bottom of independent experiments, $n=3)$. (C) pNK-2DL1 cells were incubated with 721-HLA negative cells at $37^{\circ} \mathrm{C}$ for 5 minutes, and cells were subsequently lysed. Lysates were separated on SDS page and transferred to a nitrocellulose membrane that was immunoblotted with anti-pSHP-1 S591 antibody. SHP-1 S591 phosphorylation levels were measured by densitometric analysis, relative to the GAPDH loading control using ImageJ. Samples were normalized to the pNK-2DL1 sample treated with N.S siRNA, and incubated with 721 targets $(P=0.0113$, quantification on the bottom showing the average of 3 independent experiments). Data are shown as mean \pm SEM. One sample t-tests (A, B) or one-way ANOVA with Tukey test (C) were used to calculate $\mathrm{p}$ values

Figure 4-source data 1 and Figure 4- Figure supplement 1- source data 1: Representative blots

Figure 4-source data 2 Figure 4- Figure supplement 1- source data 2: Numerical data for all graphical presentation.

\section{PKC- $\theta$ regulates SHP-1 conformation status and its enzymatic activity at the NKIS}

To determine whether SHP-1 conformation is affected by PKC- $\theta$, YTS-2DL1 cells were co-

transfected with YFP-SHP-1-CFP along with NS or PKC- $\theta$-specific siRNA, and incubated with

targets for 5 minutes. Synaptic FRET efficiency was significantly reduced in YTS-2DL1 YFP-

SHP-1-CFP cells pretreated with PKC $-\theta$ siRNA versus NS siRNA (18.5 $\pm 2.04 \%$ vs. 9.8 $\pm 1.7 \%$,

$P=0.0025$ ), suggesting that the SHP-1 in the silenced cells acquires the open conformation (Fig. 
5A, B). Interestingly, PKC- $\theta$ gene silencing reduced the FRET efficiency of YFP-SHP-1-CFP in the activating NKIS to similar FRET levels observed in YTS-2DL1 YFP-SHP-1-CFP cells pretreated with NS siRNA following inhibitory interactions $(5.76 \pm 1.6 \%$ vs. $9.8 \pm 1.7 \% P=0.2663)$, (Fig. 5 A-B). Hence, although the SHP-1 conformation in activating synapses is closed and inactive, $\mathrm{PKC}-\theta$ gene silencing increases SHP-1 open and active conformation at the activating NKIS, as detected by reduced FRET efficiency between the N' and C' termini of the SHP-1 sensor. This may suggest a role for PKC- $\theta$ in reducing SHP-1 activity at the activating NKIS, where SHP1 localizes yet is inactive, and possibly during the termination of the inhibitory synapse to enable subsequent NK cell activity.

In order to examine whether the altered SHP-1 conformation induced under PKC- $\theta$ gene silencing affects SHP-1 catalytic activity, SHP-1 activity was assessed through protein tyrosine phosphatase (PTP) assay. Direct catalytic activity of SHP-1 on the pNPP substrate was shown to be higher in cells treated with PKC- $\theta$ siRNA rather than in cells treated with NS siRNA $(81 \% \pm 3.3 \%$ vs. $65 \% \pm 3 \%$ activity, $P=0.0246$ ) (Fig.5-Fig. supplement 1 ). Collectively, these results indicate that SHP-1 phosphorylation by PKC- $\theta$ can shift the SHP-1 conformational state from open (active) to closed (inactive), and thus reduce SHP-1 enzymatic activity. 


\section{Fig. 5}

\section{A}
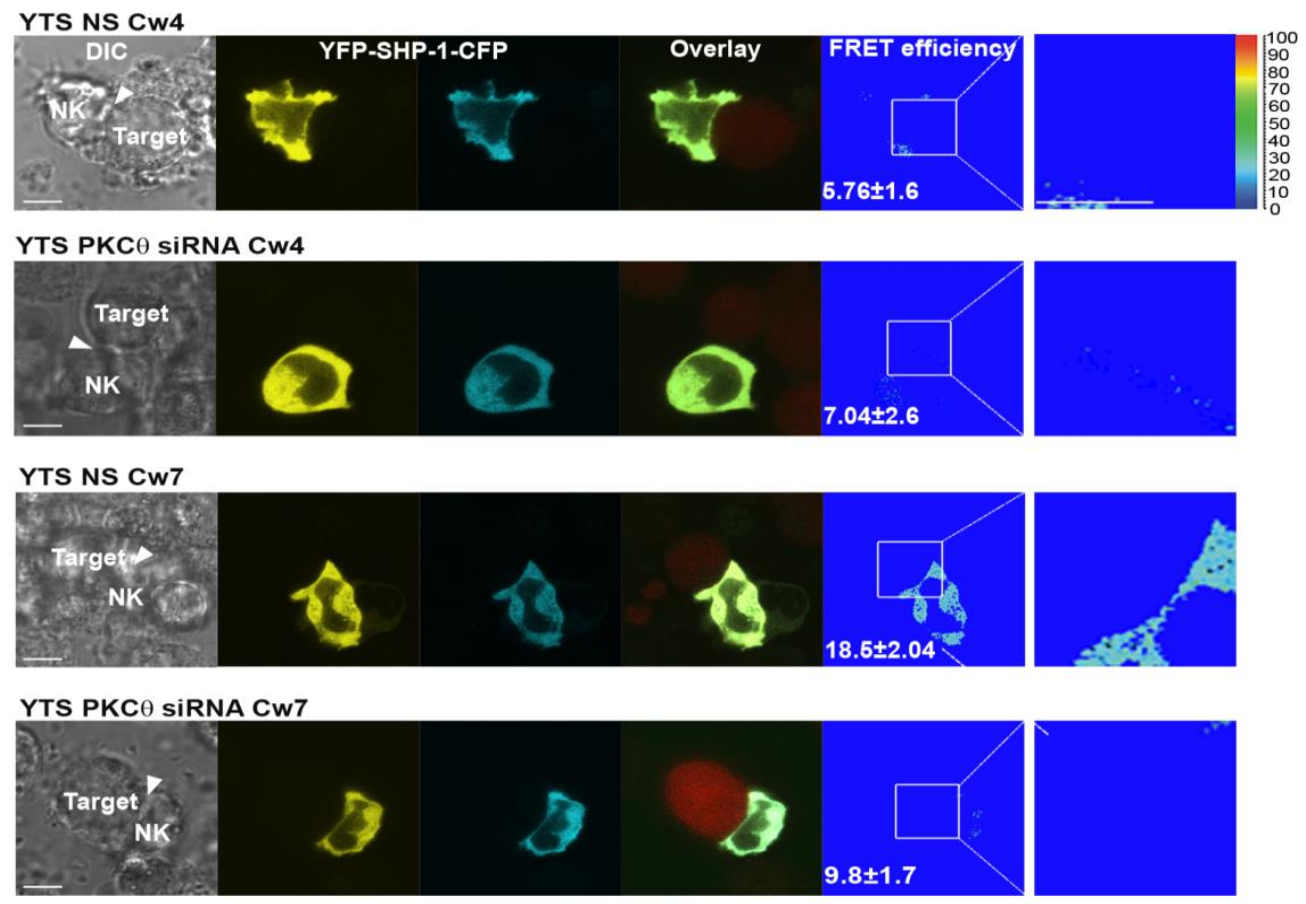

B

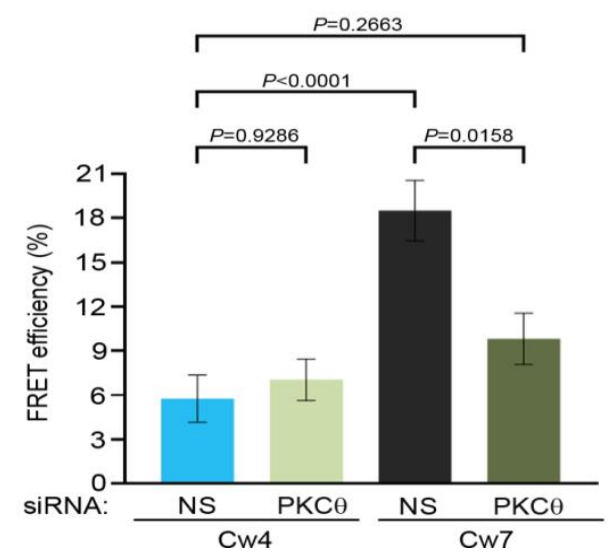

Fig. 5. SHP-1 conformation is regulated by PKC- $\theta$ at the NKIS. (A) YTS-2DL1 YFP-SHP-1-CFP cells were treated with either N.S or PKC- $\theta$ siRNA and incubated over slides pre-seeded with 721-Cw4 (top panels) or Cw7 (bottom panels) target cells expressing mCherry. The cells were incubated for 5 minutes at $37^{\circ} \mathrm{C}$ to enable conjugate formation, and were fixed. FRET analysis was performed, as indicated. (B) Graph summarizing FRET efficiency during 5 min activation with 721-Cw4 or Cw7 target cells. For Cw4 NS and PKC- $\theta$ siRNA, n=52, and 63 cell conjugates were analyzed, respectively, and for Cw7 NS and PKC- $\theta$ siRNA $n=67$, and 61 cell conjugates were analyzed from three independent experiments, respectively. Data are shown as mean \pm SEM. Two-way ANOVA with Tukey test (B) were used to calculate p values.

Figure 5-source data 1: Numerical data the graphical presentation. 


\section{SHP-1 activity is modified under PKC- $\theta$-mediated regulation}

To further characterize the ability of PKC- $\theta$ to regulate SHP-1 catalytic activity, the phosphorylation profile of key signaling proteins that serve as SHP-1 substrates was compared following $\mathrm{NK}$ cell activation or inhibition under PKC- $\theta$ gene silencing. SHP-1 was shown to dephosphorylate VAV1 as a mechanism of terminating NK cell activation(Stebbins, 2003). Furthermore, our recent studies identified novel SHP-1 substrates including PLC $\gamma 1 / 2$ and LAT(Matalon, 2016).

We therefore examined how PKC- $\theta$ gene silencing affects SHP-1 catalytic activity on its substrates in YTS and pNK-2DL1 cells. In order to assess the phosphorylation status of these proteins, cells were treated either PKC- $\theta$ siRNA or with NS siRNA and incubated with inhibitory Cw4-721 or activating Cw7-721 or 721-HLA negative target cells. IB of pVAV1 (Y160) revealed an approximately 2-fold reduction in phosphorylation levels in activated YTS-2DL1 samples treated with PKC- $\theta$ siRNA in contrast to NS siRNA ( $P=0.0001)$ (Fig. 6A). Similarly, pNK-2DL1 cells demonstrated a similar reduction in pVAV1 (Y160) phosphorylation levels subsequent to PKC$\theta$ gene silencing $(P=0.0192)$ (Fig. 6A). Furthermore, phosphorylation of VAV1 in activating interactions following $\mathrm{PKC}-\theta$ gene silencing was similar to its phosphorylation during inhibitory interactions (YTS and pNK-2DL1 cells treated with NS siRNA). In addition to VAV1, pNK-2DL1 cells showed a 1.8 fold \pm 0.2 reduction in pPLC $\gamma 1$ levels $(P=0.0032)$ when treated with PKC $-\theta$ siRNA (Fig. 6B). A similar trend can be seen in YTS-2DL1 cells in which IP of PLC $\gamma 1$ and IB of pPLC $\gamma 1$ (Y783) revealed a reduction of 1.4 fold \pm 0.04 in pPLC $\gamma 1$ levels following PKC$\theta$ gene silencing under activating interactions $(\mathrm{P}=0.0074)$ (Fig.6 -Fig. supplement 1). Together these data suggest that PKC- $\theta$-mediated regulation of SHP-1 catalytic activity may promote SHP1 inactivation, and thus enhance NK cell reactivity. 
In order to demonstrate that PKC- $\theta$ regulation of SHP-1 via S591 influences SHP-1 substrate phosphorylation and activation, and not PKC- $\theta$ silencing per-se, a mutant YTS-2DL1 line expressing a SHP-1 mutant that mimics the constitutively phosphorylated state, SHP-1 S591D, was created utilizing CRISPR/CAS9, as previously reported (Ben-Shmuel, 2020). In cells expressing this mutant, PKC- $\theta$ silencing would not be expected to impact SHP-1 activity(Egelhoff et al., 1993; Huang et al., 1994; Léger et al., 1997). Hence, we expected that the S591D mutant would demonstrate high accumulation of pVAV1 in the synapse, irrespective of PKC- $\theta$ silencing. WT YTS-2DL1 or YTS-2DL1 SHP-1 S591D NK cells were treated with either NS or PKC- $\theta$ siRNA, and incubated with mCherry-expressing target cells to assess pVAV1 Y160 synaptic accumulation. As expected, pVAV1 Y160 accumulation was observed during activating but not inhibitory NK cell interactions $(P<0.0001)$, and in accordance with our results, PKC- $\theta$ siRNA treated NK cells had a $2 \pm 0.2$ fold reduction in pVAV1 recruitment to the activating NKIS $(P<0.0001)$, indicating increased SHP-1 activity in the absence of PKC- $\theta$ under activating interactions (Fig. 6C). No significant decrease was observed, however, in pVAV1 recruitment in SHP-1 S591D NK cells treated with either NS or PKC- $\theta$ siRNA under either activating or inhibitory interactions $\left(P=0.9109, P=0.9999\right.$, respectively). Furthermore, YTS-2DL1 SHP1 ${ }^{-/}$cells were reconstituted with either YFP-SHP-1 WT or with YFP-SHP-1 mutant constructs, including the constitutively phosphorylated SHP-1 mimetic (YFP-SHP-1 S591D, constitutively inactive) or an SHP-1 phospho-abolishing mutant (YFP-SHP-1 S591A, constitutively active). YTS-2DL1 SHP-1 ${ }^{-/}$cells transfected with YFP-SHP-1 were incubated with Cw4-721 targets expressing mCherry, and stained for pPLC $\gamma 1$ (Y783) (Fig. 6D). We previously showed that pPLC $\gamma 1$ (Y783) accumulation at the NKIS is favored during activating rather than inhibitory NK cell interactions ${ }^{14}$. Interestingly, cells expressing SHP-1 S591D showed high levels of pPLC $\gamma 1$ (Y783) accumulation 
at the NKIS, even though the NKIS was inhibitory. These levels were approximately 3 fold higher compared to YTS-2DL1 cells expressing SHP-1 WT or SHP-1 S591A $(P<0.0001)$. Collectively, these results demonstrate that PKC- $\theta$ negatively regulates SHP-1 activity by phosphorylating S591, as demonstrated through higher VAV1 and PLC $\gamma 1$ tyrosine phosphorylation, and accumulation at the NK synapse. 
bioRxiv preprint doi: https://doi.org/10.1101/2021.09.06.459131; this version posted September 6, 2021. The copyright holder for this preprint (which was not certified by peer review) is the author/funder, who has granted bioRxiv a license to display the preprint in perpetuity. It is made available under aCC-BY 4.0 International license.

Fig. 6

A

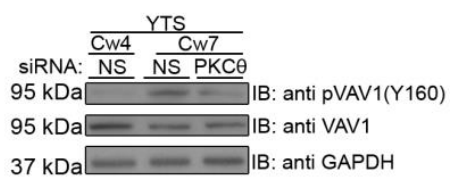

YTS

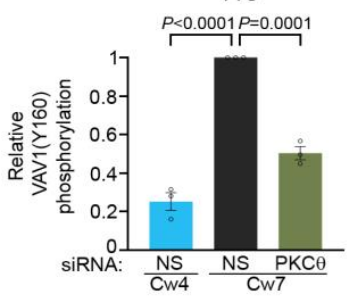

C
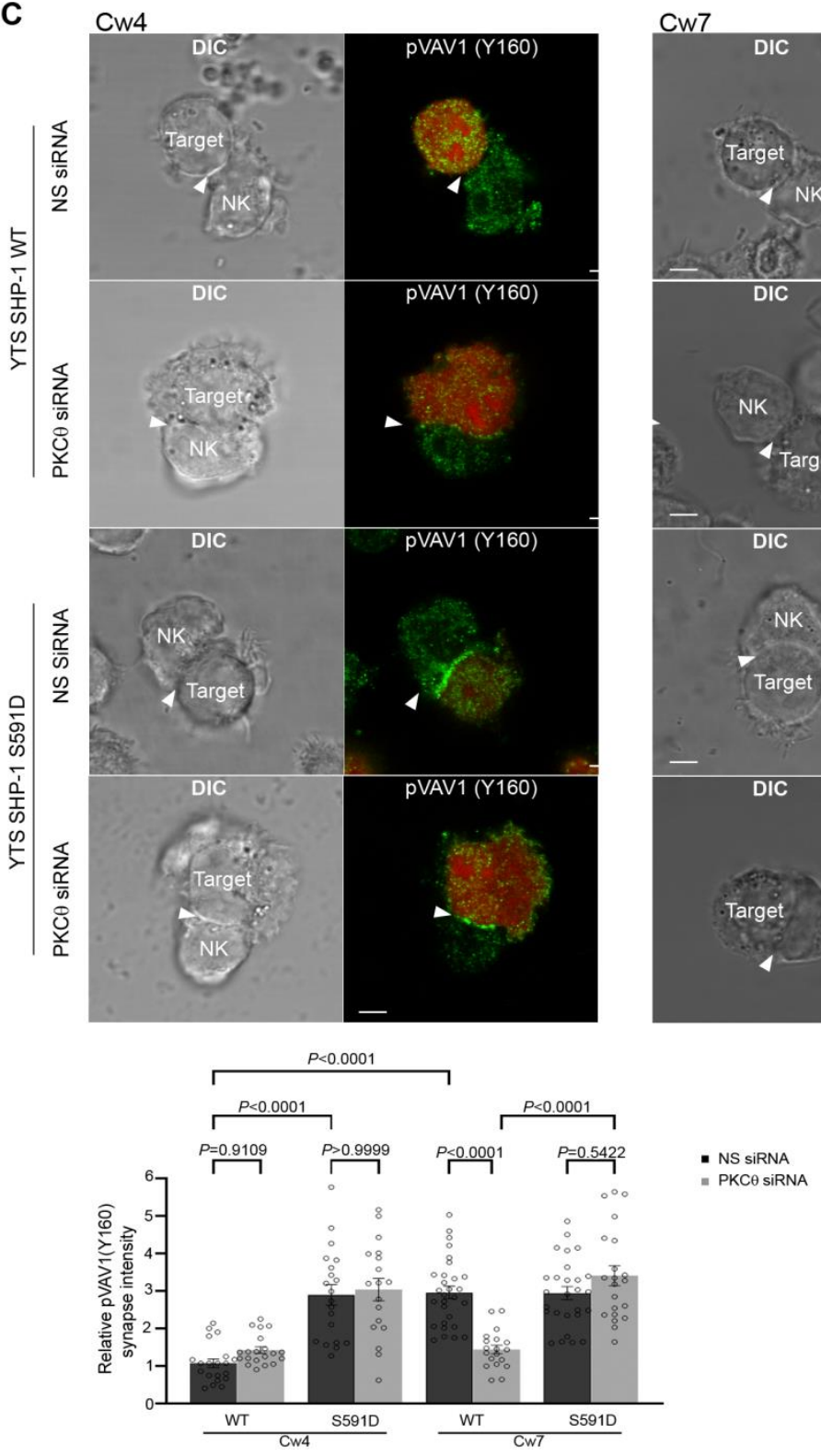

B
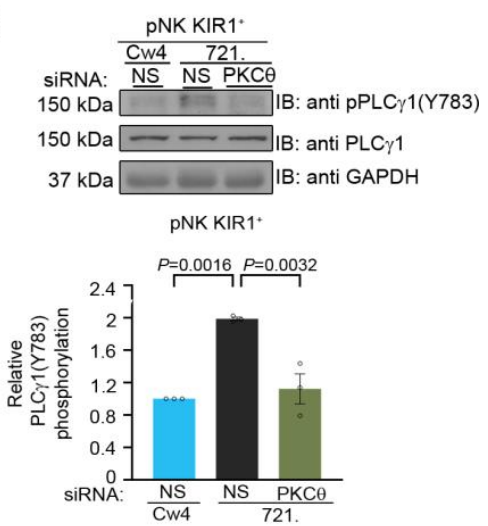
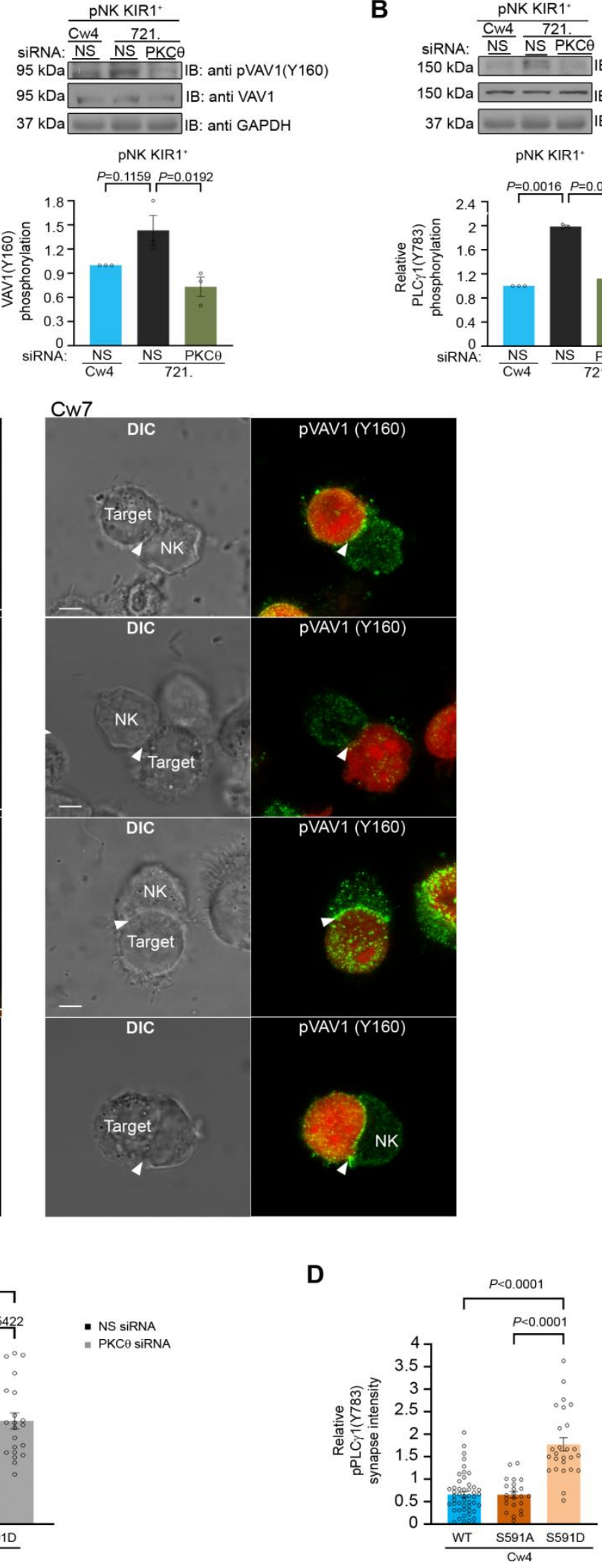
Fig 6. SHP-1 substrate phosphorylation is reduced following PKC- $\theta$ silencing. (A) YTS-2DL1 or pNK-2DL1 cells were transfected with 500 pmol of PKC- $\theta$ siRNA for $48 \mathrm{hrs}$. Cells were incubated with target cells for 5 minutes at $37^{\circ} \mathrm{C}$ and then lysed. Lysates were separated on SDS page and immunoblotted with anti pVAV-1 (Y160) antibody. Phosphorylation levels were measured by densitometric analysis, relative to the GAPDH loading control using ImageJ. Samples were normalized according to the YTS-2DL1 or pNK-2DL1 NS siRNA Cw4 sample. Quantification of independent experiments is shown on the bottom; $n=3$ for YTS and $n=4$ for $p N K$ experiments. (B) pNK-2DL1 cells were transfected with either N.S or PKC $-\theta$ siRNA $48 \mathrm{hrs}$ prior to each experiment. Cells were incubated with either 721-Cw4 or 721-HLA negative target cells for 5 minutes at $37^{\circ} \mathrm{C}$, and subsequently lysed. Lysates were separated on SDS page and immunoblotted with anti pPLC $\gamma-1$ (Y783) antibody. Phosphorylation levels were measured by densitometric analysis, relative to the GAPDH loading control using ImageJ. Samples were normalized to the pNK2DL1 NS siRNA Cw4 sample. Quantification of independent experiments is shown on the bottom; $n=3$. The blot in (B) was stripped and reblotted against pVAV-1(Y160) in (A). (C) YTS-2DL1 WT or YTS-2DL1 S591D cells were transfected with either NS or PKC- $\theta$ siRNA and incubated over slides pre-seeded with 721-Cw4 or Cw7 target cells expressing mCherry. The cells were incubated for 5 minutes at $37^{\circ} \mathrm{C}$ to enable conjugate formation, and fixed. pVAV1 (Y160) was subsequently labeled with primary rabbit anti-pVAV-1 (Y160) antibody and secondary anti-rabbit 488 antibody. Quantification is shown on the bottom; for YTS-2DL1 WT NS or PKC- $\theta$ siRNA vs. Cw4 and Cw7, $\mathrm{n}=21$ and 28 cell conjugates were analyzed, respectively. For YTS-2DL1 S591D NS or PKC- $\theta$ siRNA vs. Cw4 and Cw7, $\mathrm{n}=21$ and 28 cell conjugates were analyzed from three independent experiments, respectively. (D) YTS-2DL1 SHP$1^{-1-}$ cells were transfected with either WT YFP-SHP-1, S591A YFP-SHP-1, or S591D YFP-SHP-1 phosphorylation mutants and incubated on slides with mCherry expressing $721-\mathrm{Cw} 4$ target cells at $37^{\circ} \mathrm{C}$. After 5 min incubation, the cells were fixed and stained with anti-pPLC $\gamma-1$ (Y783) and secondary Alexa-488 antibody; accumulation of phosphorylated PLC $\gamma-1$ at the NKIS was determined. NK cells were distinguished from targets based on mCherry expression by the target cells. Graph summarizes the relative synapse staining intensities. For WT YFP-SHP-1, S591A YFP-SHP-1, and S591D YFP-SHP-1, n= 48, 48, and 25 cell conjugates from three independent experiments analyzed, respectively. Data are shown as mean \pm SEM. One-way ANOVA with Tukey test (A, B, D) or two-way ANOVA with Tukey test $(\mathrm{C})$ were used to calculate $\mathrm{p}$ values

Figure 6-source data 1 and Figure 6-Figure supplement 1-source data 1: Representative blots

Figure 6-source data 2 and 3 Figure 6-Figure supplement 1-source data 1: Numerical data for all graphical presentation.

\section{PKC- $\theta$-mediated regulation of SHP-1 augments NK cell activation}

SHP-1 tunes NK cell activation, and, as we demonstrated here, PKC- $\theta$-mediated phosphorylation

of SHP-1 impacts its enzymatic activity. We therefore next determined the effect of PKC- $\theta$

regulation on $\mathrm{NK}$ cell effector function and activation. PKC- $\theta$ silencing in NK cells resulted in a

decrease in the phosphorylation profile of VAV1 and PLC $\gamma 1$ in a SHP-1 dependent manner (Fig.

6). These data suggest that the PKC- $\theta$ :SHP-1 axis may affect $\mathrm{NK}$ cell activation and cytotoxicity,

in a manner that is highly dependent on calcium flux and actin reorganization(Orange et al., 2002;

Stebbins, 2003; Bryceson et al., 2006; Caraux et al., 2006; Upshaw et al., 2006; Andzelm et al.,

2007; Kim et al., 2010; Dong et al., 2012; Mizesko et al., 2013; Carisey et al., 2018). To this end,

PKC- $\theta$ was gene-silenced in YTS-2DL1 cells, and intracellular calcium flux was measured in NK 
cells incubated with activating 721-Cw7 target cells. As expected, calcium flux levels were higher in activated vs. inhibited NK cells treated with NS siRNA (black vs. blue curve, Fig. 7A). However, PKC- $\theta$ siRNA reversed this trend, reducing calcium flux levels during NK cell activation near the levels obtained during NK cell inhibition (green vs. blue curve, Fig. 7A). Similar results were obtained in pNK-2DL1cells transfected with NS or PKC- $\theta$ siRNA and incubated with activating 721-HLA negative or 721-Cw4 expressing cells (Fig.7 -Fig. supplement 1). These results are consistent with the reduced phosphorylation levels of the calcium regulator, PLC 1 (Fig. 6B and D and Fig. 6- Fig. supplement 1).

To assess how the PKC- $\theta$ :SHP-1 regulation controls NK cell cytotoxic potential, YTS-2DL1 cells were gene silenced for PKC- $\theta$ and incubated with $721-\mathrm{Cw} 4$ or $\mathrm{Cw} 7$ target cells, and target cell lysis was measured through Met release assay $\left[{ }^{35} \mathrm{~S}\right]$ a direct measurement of NK cell killing of cancerous cells (Fig. 7B). Target cell death was significantly reduced in YTS-2DL1 samples that were gene silenced for PKC- $\theta$ under activating interactions $(22 \% \pm 3 \%$ vs. $42 \% \pm 0.4 \%$, $P=0.0037)$. In fact, activating target cells $(\mathrm{Cw} 7)$ incubated with $\mathrm{PKC}-\theta$-silenced $\mathrm{NK}$ cells demonstrated lysis levels similar to those of inhibitory targets (Cw4) incubated with YTS-2DL1 cells treated with NS siRNA $(22 \% \pm 3 \%$ vs. $13 \% \pm 2.7 \%, P=0.1015)$. These data were verified in human primary NK cells treated with NS or PKC- $\theta$ siRNA $(5.5 \% \pm 1.6 \%$ vs. $18 \% \pm 1.06, P=0.0021$, and $5.5 \% \pm 1.6 \%$ vs. $10 \% \pm 1.32 \%, P=0.2$ ) (Fig. 7C and Fig.7-Fig. supplement 1). To verify that absence of PKC- $\theta$ influences NK cell effector functions through SHP-1 activity, and that the effects of PKC- $\theta$ silencing are abrogated in the absence of SHP-1, SHP-1 ${ }^{-/}$NK cells were additionally gene silenced for PKC- $\theta$ (Fig. 7D). Subsequently, WT and SHP-1/- NK cells either treated with NS or PKC- $\theta$ siRNA were subjected to CD107a degranulation assay. As can be seen in Fig. 7D, NK cells that were deficient in SHP-1 or both SHP-1 and PKC- $\theta$ displayed higher 
degranulation than WT cells $(P=0.0127$ and $P=0.0001)$, and were not significantly influenced by the presence or absence of PKC $-\theta(P=0.0603)$. Taken together, these data demonstrate that PKC$\theta$ negatively regulates SHP-1 conformational state and activity, thereby serving as a mechanism for maintaining NK cell activation and cytotoxic potential. 


\section{Fig. 7}

A

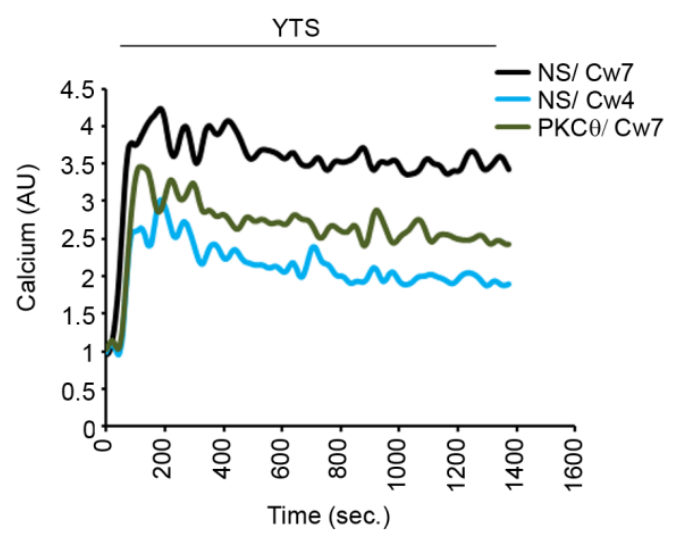

C

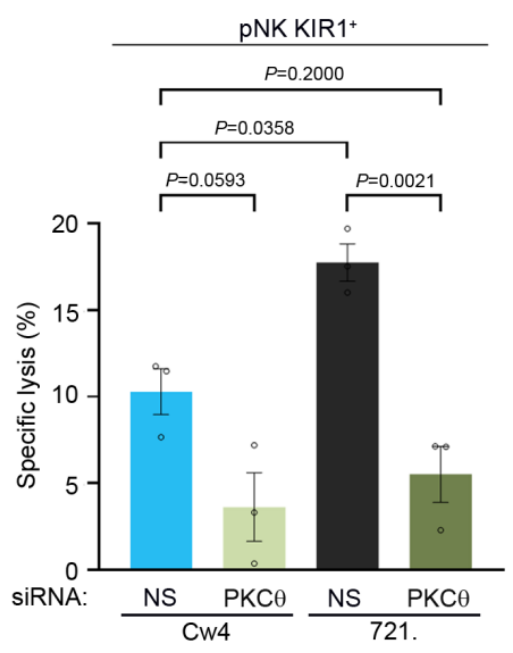

B

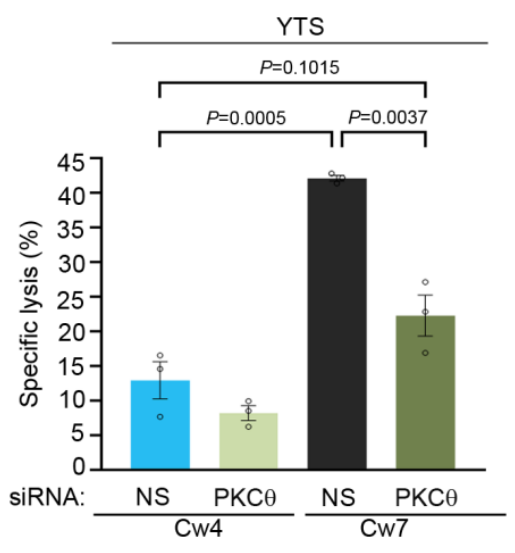

D

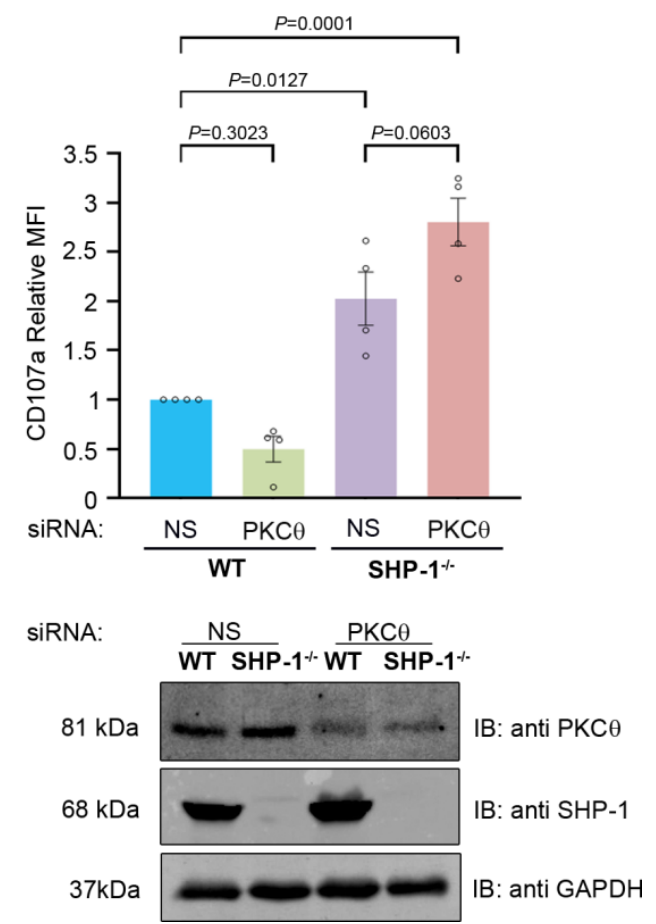

Fig 7. NK cell activation threshold is increased following gene silencing of PKC- $\theta$. YTS-2DL1 cells were transfected with specific PKC- $\theta$ siRNA or with N.S siRNA and used after 48 hrs. (A) YTS-2DL1 cells were loaded with calcium- sensitive Fluo-3-AM, and analyzed for basal intracellular calcium levels for 1 minute. The NK cells were then mixed with $721-\mathrm{Cw} 4$ or $\mathrm{Cw} 7$ target cells and incubated at $37^{\circ} \mathrm{C}$ and analyzed by spectrofluorometry. (B) YTS-2DL1 cells were incubated with $\left.{ }^{35} \mathrm{~S}\right]$ Met labeled $721-\mathrm{Cw} 4$ or $\mathrm{Cw} 7$ target cells at a ratio of 10:1 for 5 hours at $37^{\circ} \mathrm{C}$. The specific lysis of target cells was measured. The graph summarizes 3 independent experiments. (C) pNK$2 \mathrm{DL} 1$ cells were incubated with $\left[{ }^{35} \mathrm{~S}\right]$ Met labeled $721-\mathrm{Cw} 4$ or HLA negative target cells at a ratio of 10:1 for 5 hours 
at $37^{\circ} \mathrm{C}$. The specific target cell lysis was measured. The graph shows the average of 3 independent experiments. (D) WT YTS-2DL1 or YTS-2DL1 SHP- $1^{-1-}$ cells were treated with either NS or PKC- $\theta$ specific siRNA 24 hours before incubation with mCherry-expressing $721-\mathrm{Cw} 4$ target cells for 2 hours at $37^{\circ} \mathrm{C}$, and analyzed for degranulation via FACS relative to the WT NS treated cells incubated with 721-Cw4 targets, as described in the Materials and Methods. A representative blot is shown (bottom) demonstrating PKC- $\theta$ and SHP-1 expression; the graph shows the average of 4 independent experiments. Data are shown as mean \pm SEM. Two-way ANOVA with Tukey test $(B, C)$ or one -way ANOVA with Tukey test (D) were used to calculate $p$ values.

Figure 7-source data 1 and Figure 7-Figure supplement 1-source data: Numerical data for all graphical presentation.

Figure 7-source data 2: Representative blots

\section{SHP-1 deficient NK cells are unaffected by PKC- $\theta$ silencing, and promote superior anti-}

\section{tumor clearance relative to WT cells.}

We recently demonstrated that abrogation of SHP-1 activity in engineered NK cells can have enhanced benefits for NK-based immunotherapeutic approaches(Ben-Shmuel, 2020). To verify that NK cells silenced for PKC $-\theta$ have lower anti-tumor cytotoxicity due to enhanced SHP-1 activity, and not due to absence of PKC- $\theta$ per se, NOD-Rag $1^{\text {null }}$ IL2rg ${ }^{\text {null }}$ (RAG) immunodeficient mice were subcutaneously engrafted with $721-\mathrm{Cw} 4 / \mathrm{Cw} 7$ cells and injected with either $3 \times 10^{6} \mathrm{WT}$ YTS-2DL1, WT YTS-2DL1 that were treated with PKC- $\theta$ siRNA, YTS-2DL1 SHP-1 deficient cells(Matalon, 2018) or YTS-2DL1 SHP-1 deficient cells that were treated with PKC- $\theta$ siRNA, every 3 days for a total of six treatments. Tumor volumes were monitored daily to examine the effect on tumor size and average growth rate. If $\mathrm{PKC}-\theta$ affects $\mathrm{NK}$ cell cytotoxicity in a dominant alternative pathway to SHP-1, then the observed phenotype of SHP-1 silenced/mutated NK cells (highly increased killing and perturbation of tumor growth) would be expected be abrogated, at least moderately, upon PKC- $\theta$ silencing. Indeed, mice injected with YTS-2DL1 SHP-1 deficient/catalytically inactive cells that were treated with PKC $-\theta$ siRNA demonstrated slower tumor growth rate and smaller tumor volumes compared to mice injected with WT NK cells (Fig. 
8). Thus, regulation of SHP-1 through PKC- $\theta$ impacts NK cell cytotoxicity and affects NK cell capability for in-vivo tumor clearance.

Fig. 8

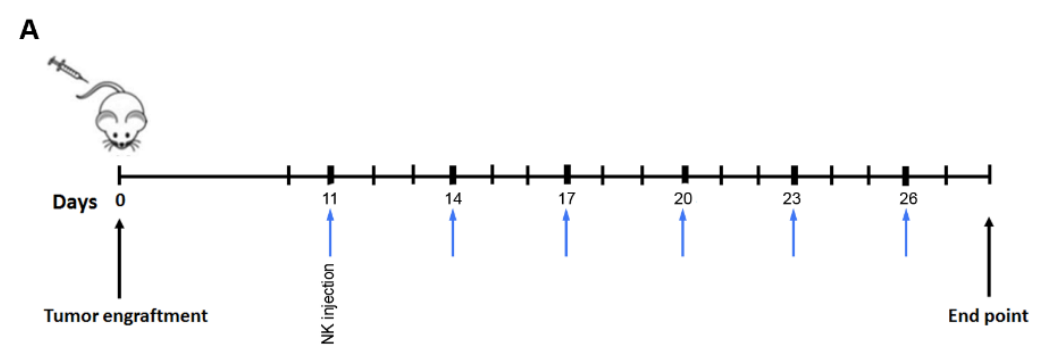

B

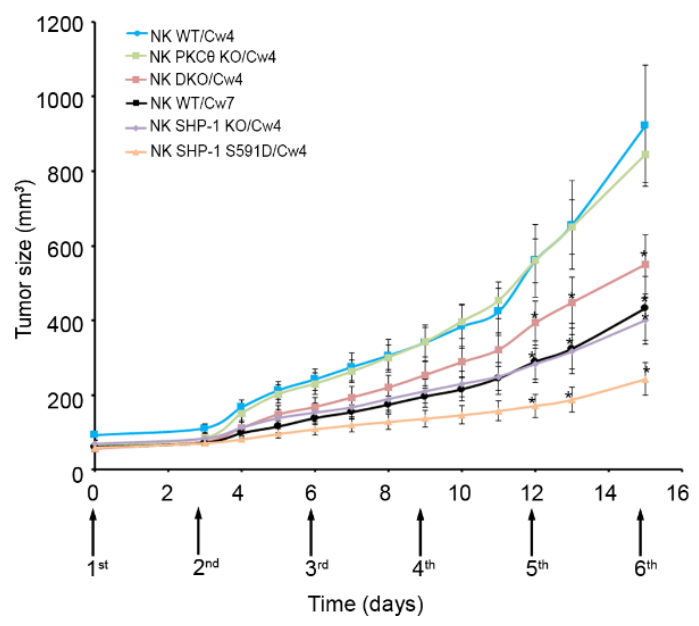

C
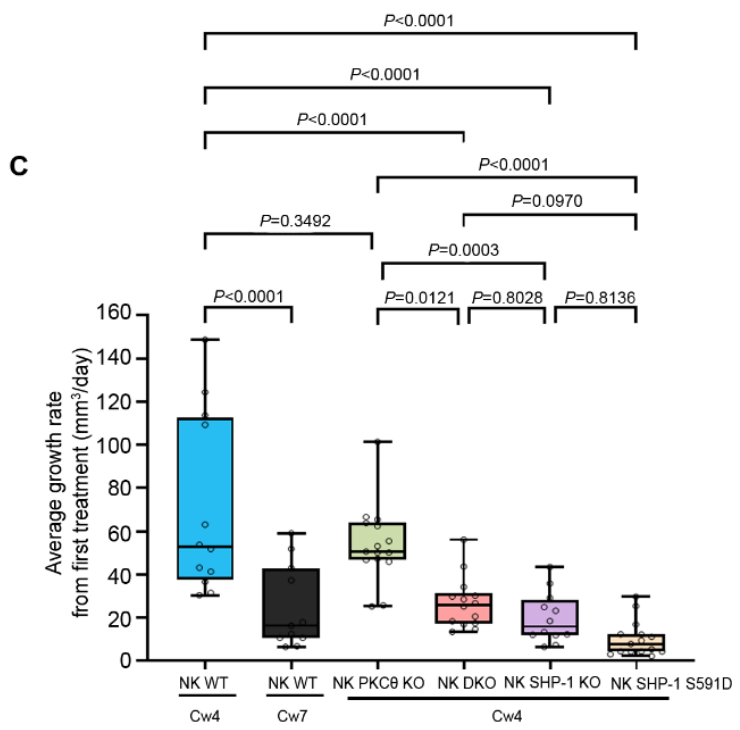

Fig. 8. SHP-1 deficient NK cells exhibit enhanced anti-tumor activity in vivo, irrespective of PKC- $\theta$ expression. (A) Schematic representation of the experimental timeline. (B) Tumor volumes measured daily in NODRag1 ${ }^{\text {null } I L 2 r g}{ }^{\text {null }}$ (RAG) mice. NOD-Rag1 ${ }^{\text {null }} I L 2$ rg $^{\text {null }}$ (RAG) mice were subcutaneously injected with $3 \times 10^{6} 721-C w 4$ or Cw7 expressing tumor cells. Mice were administered by intratumor injections every 3 days with either $3 * 10^{6}$ irradiated WT YTS-2DL1, WT YTS-2DL1 that were treated with PKC- $\theta$ siRNA (NK PKC- $\theta$ KO), YTS-2DL1 SHP1 deficient cells (NK SHP-1 KO) or YTS-2DL1 SHP-1 deficient cells that were treated with PKC- $\theta$ siRNA (NK DKO). (C) Average growth rates of tumors from the first treatment to the end point. Tumor volumes and tumor growth rates were calculated as described in the Methods. Data are shown as mean \pm SEM. Two-way ANOVA with Tukey test $(\mathrm{B}, \mathrm{C})$ were used to calculate $\mathrm{p}$ values.

Figure 8-source data 1: Numerical data for all graphical presentation. 


\section{Discussion}

SHP-1 plays a central role in the regulation of NK cell activation threshold(Stebbins, 2003; Lanier, 2005; Long, 2008; Matalon, 2016) and is critical for the NK cell education process(Viant et al., 2014). Importantly, activation of SHP-1 and its homolog SHP-2 (an additional critical inhibitory NK cell regulatory enzyme(Purdy et al., 2009)) are the major mechanisms operating downstream to immune checkpoint receptors, such as PD-1, CTLA-4, BTLA, and LAG-3(Lee et al., 1998; Watanabe et al., 2003; Sheppard et al., 2004; Huang et al., 2015). It is therefore of great interest to understand how this important regulator is kept in check during NK cell activation and inhibition, as this regulatory mechanism may have critical consequences for additional immune cells, immune checkpoint pathways, and immunotherapies.

NK cell activity is regulated by a balance between stimulatory or inhibitory signals, yet how these signals are integrated, and how intracellular NK cell activation is maintained and controlled through these multiple receptors remains incompletely understood. Moreover, the presence of SHP-1 at the activating NKIS and rapid dispersal from the inhibitory NKIS(Vyas, 2002a) suggest as yet unknown roles and regulatory mechanisms. Here, we elucidate these unresolved mechanisms by showing that the NK cell activation threshold is maintained through downregulation of SHP-1 phosphatase activity regulated by $\mathrm{PKC}-\theta$.

Studies published on outcomes of SHP-1 $C^{\prime}$ terminal serine phosphorylation in non-NK cell systems demonstrated contradicting results(Li, 1995; Brumell et al., 1997; Jones, 2004; Poole, 2005; Liu, 2007). Here, we demonstrate that phosphorylation of SHP-1 by PKC- $\theta$ during NK cell activation on serine 591 maintains heightened NK cell effector function by retaining the SHP-1 closed and inactive conformation. This mechanism preserves SHP-1 substrate phosphorylation, and consequently sustains calcium flux and cytotoxicity. Thus the PKC- $\theta$ : SHP-1 axis may play 
an important role in NK immune surveillance and tumor clearance, a topic that has recently gained much attention in the immunotherapy field, especially in the context of adoptive cell transfer and genetically engineered NK cells(Dotta et al., 2007; Morandi et al., 2008; Ahern et al., 2011; Jochems et al., 2016; Siegler et al., 2017).

Our findings may answer an important question regarding how SHP-1 activity is down modulated after dissociation of the inhibitory NKIS, and how its signaling is downregulated during cytolytic NK responses. Phosphorylation of SHP-1 during termination of the inhibitory NKIS may retain the activity of NK cells to subsequent targets, whereas its immediate phosphorylation at the activating NKIS maintains the NK cell lytic capacity. This is consistent with the SHP-1 conformation patterns shown here (Fig. 2) within the activating and inhibitory NKIS.

Interestingly, mathematical modeling analysis in NK cells suggest that weak ligands for activating receptors (bearing partially phosphorylated ITAMs) can recruit SHP-1 and thereby increase the NK activation threshold, while under certain conditions (such as low concentration of SHP-1 and weak activating ligands) inhibitory receptors can aid in NK cell activation(Das, 2010). Thus, it is possible that one mechanism facilitating target cell escape from NK cell lysis is selection for cells expressing weak activating ligands which induce SHP-1 recruitment. It is clear that the transition of SHP-1 between inhibiting and activating receptors must be tightly regulated to ensure proper NK cell responses.

PKC $-\theta$ is the only PKC isoform that was shown to accumulate at T-cell and NK cell synapses(Merino, 2012)'(Monks et al., 1997). In T cells, it is clear that PKC- $\theta$ plays important role in $\mathrm{T}$ cell activation and survival by activating several downstream pathways, including NFkB and AP-1 as major targets(Wang et al., 2015). In addition, Merino et al previously showed that clustering of PKC- $\theta$ at the NKIS amplifies murine NK cell activation and effector 
functions(Merino, 2012), but the mechanism by which it exerts this function and specifically in human cells remained mostly unknown. Several studies suggest the involvement of PKC- $\theta$ in signal transduction , anti-tumoral activity and NK cell degranulation(Anel, Juan I. Aguiló, et al., 2012). Here we demonstrate that in human NK cells, PKC- $\theta$ phosphorylates SHP-1 on S591 (Fig. 4, Fig.3-Fig. supplement 1C), suppresses SHP-1 activity, and thereby increases NK cell activity. PKC- $\theta$ appears to regulate SHP-1 activity during the late inhibitory synapse and through the full duration of activating NK: target cell interactions. Indeed, gene silencing of PKC- $\theta$ resulted in the closed SHP-1 conformation (Fig. 5), implying that SHP-1 favors an open and active conformation in the absence of PKC- $-\theta$. This conformational change in SHP-1 also impacts its catalytic activity. These findings were strengthened through in-vivo experiments, which demonstrated that absence of SHP-1 increased NK cell activity and decreased tumor progression, irrespective of PKC- $\theta$ expression, implying that $\mathrm{PKC}-\theta$ indeed maintains $\mathrm{NK}$ cell activation through its regulation of SHP-1.

Several studies show that deficiency or inhibition of PKC- $\theta$ could potentially decrease the severity of autoimmunity, allergy and chronic inflammation. For example in animal models of intestinal inflammatory disease (chronic colitis), PKC- $\theta \mathrm{KO}$ mice showed decreased $\mathrm{T}$ cell proliferation and cytokines production(Chand et al., 2012; Curnock et al., 2014; Nicolle et al., 2021) suggesting that PKC $-\theta$ inhibitors could be useful as a therapeutic approach for inflammatory disorders(Chand, 2012; Curnock, 2014).

Though pSHP-1 levels were substantially reduced after PKC- $\theta$ gene silencing, basal levels were still evident. It is possible that other serine/threonine kinases or isoforms such as PKC- $\alpha$ may also be involved in this process $(\vartheta \circ v \varepsilon \sigma, 2004)$. Another possible mechanism may involve PKC $-\theta$ cross talk with the NK cytoskeleton. We recently demonstrated that SHP-1 conformation and activity is 
dependent on association to the cytoskeletal machinery and cytoskeletal dynamics(Matalon, 2018).

One possibility is that crosstalk between PKC $-\theta$ and SHP-1 mediates actin: SHP-1 binding or disassociation, thereby regulating SHP-1 catalytic activity and conformation. Furthermore, PKC $-\theta$ phosphorylates the Wiskott-Interacting Protein (WIP) in NK cells upon activation, and this facilitates recruitment of actin and myosin IIA to WIP and WASp for formation of the multi protein complex(Krzewski et al., 2006). Hence PKC- $\theta$ activity could affect acto-myosin dynamics and velocity at the NKIS, influencing SHP-1 activity. It would thus be interesting to elucidate how the interaction of SHP-1 with the cytoskeletal machinery changes as a function of PKC- $\theta$ activity.

After SHP-1 mediates its function and prevents NK cell activity during an inhibitory interaction, its activity should be downregulated to enable subsequent NK cell interactions with activating susceptible targets. This can be seen by late phosphorylation (after 20 minutes) of SHP-1 S591 during inhibitory NK cell synapses (Fig. 1), and may serve as a mechanism of kinetic priming, ensuring that NK cell activity remains stable for future contacts(Choi, 2013).

Recently it was shown that as NK cells are constantly situated in an environment that requires simultaneous killing of target cells and sparing of others, accurate and specific convergence of lytic granules aids in killing only relevant targets, while sparing healthy cells(Hsu, 2016). Moreover, a study by Netter et al demonstrated how initiation and termination of the activating NKIS is highly regulated, and enables serial NK cell killing by accelerating detachment from one target cell and simultaneous formation of new cytotoxic NK cell synapses(Netter, 2017). Additional reports by Srpan et al. describe NK cell serial killing via shedding of surface receptors(Srpan, 2018). Thus, sequential and highly regulated signaling is needed for NK cell maneuverability in a complex immune environment. PKC- $\theta$;SHP1 regulation may enable an NK cell to rapidly survey its surroundings and maintain its effector functions in a complex immune 
environment that requires simultaneous sparing of normal cells, and killing of malignant targets. This mechanism would also ensure that NK cell effector functions are maintained in the presence of an activating NK cell synapse. Cancer cells can express MHC-I and other inhibitory NK cell ligands; thus, recruitment and activation of PKC- $\theta$ at the activating NKIS may limit SHP-1 association to ITIMs that could prevent tumor cell killing. It would be interesting to assess the effect of S591 phosphorylation on SHP-1:KIR ITIM association, as this phosphorylation may not only affect the NK cell activation threshold, but also NK cell education, as SHP-1 was shown to be vital for regulating NK cell responsiveness to tumors(Viant, 2014).

Due to the fact that NK cells are also implicated in auto immune disorders such as multiple sclerosis(Morandi, 2008), rheumatoid arthritis(Ahern, 2011), and type I diabetes (Dotta, 2007), deregulation of SHP-1 activity may be a factor affecting normal NK cell functions against healthy cells. SHP-1 was also shown to serve as an important transcription factor that impacts cell proliferation and survival. Some studies examined its role in tumor transformation(Wu et al., 2003). It would be interesting to examine whether mutations or regulation of SHP-1 S591 or other known or as yet unidentified residues may impact its function. Understanding regulatory protein circuits in NK cells will be an important step for further elucidating complex pathways such as NK signaling cascades and NK cell education, and potentially open doors to innovative immunotherapies shaping NK cell behavior. 


\section{Materials and Methods}

\section{Cell lines and reagents}

The following cells were used in this study: YTS NK cell line expressing the inhibitory KIR2DL1 (referred as YTS-2DL1), B-cell lymphoma, 721.221 cells (referred as 721) expressing no HLA, and 721 cells expressing either HLA-Cw4 or $-\mathrm{Cw} 7$, and K562. These cells were kindly provided by Prof. Ofer Mandelboim (Department of Microbiology and Immunology, Faculty of Medicine, Hebrew University of Jerusalem, Israel). YTS cells were cultured in Iscove's medium supplemented with $10 \%$ fetal bovine serum (FBS), $2 \mathrm{mM} \mathrm{L-glutamine,} 50 \mu \mathrm{g} / \mathrm{ml}$ penicillin, $50 \mu \mathrm{g} / \mathrm{ml}$

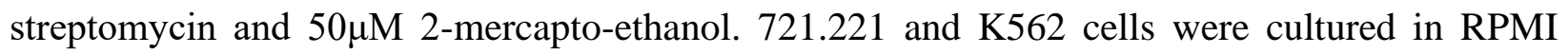
supplemented with $10 \% \mathrm{FBS}, 2 \mathrm{mM}$ L-glutamine, $50 \mu \mathrm{g} / \mathrm{ml}$ penicillin, $50 \mu \mathrm{g} / \mathrm{ml}$ streptomycin, $1 \%$ non-essential amino acids, and $1 \%$ sodium pyruvate.

\section{Antibodies}

Antibodies and their sources were as follows: Mouse anti- PLC $\gamma 1$ (Upstate), Mouse anti-VAV1 (D7), Rabbit anti-SHP-1 and Mouse anti-GAPDH (Santa Cruz), Rabbit anti-pSHP-1 (S591) (ECM Biosciences), Rabbit anti-pPLC $\gamma 1$ (Y783) (Bio Source), Rabbit anti-pVAV1 (Y160) (Bio Source), and Mouse anti-PKC- $\theta$ (Santa Cruz). Secondary antibodies: Goat anti-Mouse (Sigma-Aldrich), Goat anti-Rabbit (Santa Cruz).

\section{Primary NK cells}

Primary NK cells were isolated from peripheral blood lymphocytes (PBLs) of healthy donors using the EasySep ${ }^{\mathrm{TM}}$ human NK Cell enrichment kit (STEMCELL Technologies). Subsequently, KIR2DL1 expressing cells were isolated by staining the entire NK cell population with anti-KIR1PE antibody (Miltenyi Biotec) followed by magnetic separation using the EasySep ${ }^{\mathrm{TM}}$ human PE 
selection kit (STEMCELL Technologies) according to the manufacturer's instructions. NK cell isolation efficiencies were $>95 \%$. The NK cells were plated in 96-well U-bottomed plates and grown in the presence of irradiated PBLs from two donors $\left(5 \times 10^{4}\right.$ cells from each donor per well) as feeder cells. Cells were expanded in a complete medium containing $1 \mu \mathrm{g} / \mathrm{ml}$ of PHA, and 400 U/ml rhuIL-2 (Prospec). Before experiments, cells were washed to remove the PHA and IL-2, and cultured 48 hours in 60\% Dulbecco's modified Eagle medium (DMEM) and 25\% F-12 medium supplemented with $10 \%$ human serum, $2 \mathrm{mM}$ L-glutamine, $50 \mu \mathrm{g} / \mathrm{ml}$ penicillin, $50 \mu \mathrm{g} / \mathrm{ml}$ streptomycin, $1 \%$ non-essential amino acids and $1 \%$ sodium pyruvate.

\section{CRISPR/CAS9 mediated gene knockdown and S591D point mutation}

CRISPR/CAS9 knockdown of SHP-1 in YTS cells was conducted according to published protocol and was performed as described in detail (Ran et al., 2013; Matalon, 2018; Ben-Shmuel, 2020). The pSpCas9(BB)-2A-GFP (PX458) vector was purchased from Addgene (plasmid \# 48138). RNA guide sequences targeted to the SHP-1 locus and for knock-in of the S591D mutation were constructed using an online CRISPR design tool (Zhang Lab).

\section{RNA interference}

Small interfering RNA (siRNA) to human 3' UTR PKC- $\theta$ was purchased from Sigma Aldrich. YTS-2DL1 cells were transfected with siRNA specific for the indicated genes, or non-specific (NS) siRNA as a control, using an AMAXA electroporator.

For knockdown of PKC- $\theta$ gene expression, pools of independent specific siRNA oligonucleotides were as follows: 


\section{5' CUCUUCACCUGGGCGCCAADTDT 3'}

\section{5' UUGGCGCCCAGGUGAAGAG 3'}

Non-specific siRNA: Pools of nontargeting (nonspecific), negative control siRNA duplexes were obtained from Dharmacon with the following sequences: 5' UAGCGACUAAACACAUCAA 3', 5’UAAGGCUAUGAAGAGAUAC3', 5'AUGUAUUGGCCUGUAUUAG3',5' AUGAACGUGAAUUGCUCAA 3', and 5'UGGUUUACAUGUCGACUAA3'

\section{Cellular imaging by confocal microscopy}

Dynamic fluorescence and differential interference contrast microscopy (DIC) images of NKtarget conjugates were collected using a Zeiss 510 Meta confocal microscope. All images were collected using a 63 X Plan-Apochromat objective (Carl Zeiss).

Chambered cover slips (LabTek) were cleaned by treatment with $1 \mathrm{M} \mathrm{HCl}, 70 \%$ ethanol for 30 min and dried at $60^{\circ} \mathrm{C}$ for $30 \mathrm{~min}$. The chambers were treated with a $0.01 \%(\mathrm{wt} / \mathrm{vol})$ poly-L-lysine solution (Sigma) for $5 \mathrm{~min}$, drained, and dried at $60^{\circ} \mathrm{C}$ for $30 \mathrm{~min}$.

For NK-target conjugation assays, $5 \times 10^{5}$ target cells were seeded over the bottom of the chamber in $300 \mu \mathrm{l}$ Optimem medium for 2 hours at $37^{\circ} \mathrm{C}$, after which nonadherent cells were rinsed. Then, $5 \times 10^{5}$ NK cells were seeded over the chambers, containing imaging buffer (RPMI medium with 25mM HEPES without phenol red or serum), and allowed to form conjugates with the target cells for the indicated times at $37^{\circ} \mathrm{C}$. Following activation, the cells were fixed for 30 min with $2.5 \%$ paraformaldehyde, and washed twice with PBS. The NK and target cells in the conjugates were distinguished according to fluorescence signal, with the target cells expressing mCherry. For evaluation of phosphoprotein accumulation at the NKIS, cells were permeabilized with $0.1 \%$ Triton X-100 for 5 min. Cells were then blocked for 1 hour in PFN buffer (PBS without Ca2+ and 
$\mathrm{Mg}^{+}$and containing $10 \%$ FBS and $0.02 \%$ azide) with $2 \%$ normal goat serum (Jackson ImmunoResearch). Cells were incubated for 1 hour with the appropriate primary antibodies diluted in blocking medium, followed by staining with isotype-specific, Alexa Fluor-conjugated antibodies for $30 \mathrm{~min}$. Cells were washed three times with PFN between steps. The relative fluorescence intensities of the proteins at the NKIS were determined by measuring the ratio between the fluorescence intensity at the NKIS, relative to that at a non-NKIS site using ImageJ software.

\section{Image processing and quantification}

The acquired images were extracted with the LSM browser (Carl Zeiss), cropped and composed into Figures using Adobe Photoshop.

\section{FRET analysis}

FRET was measured by the donor-sensitized acceptor fluorescence technique as previously described(Barda-Saad, 2005; Pauker, 2012; Fried, 2014). Briefly, three sets of filters were used: one optimized for donor fluorescence (excitation, $458 \mathrm{~nm}$, and emission, 465 to $510 \mathrm{~nm}$ ), a second for acceptor fluorescence (excitation, $514 \mathrm{~nm}$, and emission, 530 to $600 \mathrm{~nm}$ ), and a third for FRET (excitation, $458 \mathrm{~nm}$; emission, 530 to $600 \mathrm{~nm}$ ).

\section{FRET correction}

FRET correction was performed as described in detail(Barda-Saad, 2005; Pauker, 2012; Fried, 2014). The non-FRET components were calculated and removed using calibration curves derived from images of single-labeled CFP- or YFP- expressing cells. Sets of reference images were obtained using the same acquisition parameters as those used for the experimental FRET images. To correct for CFP "bleed through," the intensity of each pixel in the CFP image from CFP- 
expressing cells was compared to the equivalent pixel in the FRET image of the same cells. A calibration curve was derived to define the level of CFP fluorescence seen in the FRET image as a function of the fluorescence in the CFP image. A similar calibration curve was obtained defining the amount of YFP fluorescence appearing in the FRET image as a function of the intensity in the YFP image, using images of cells expressing only YFP. Separate calibration curves were derived for each set of acquisition parameters used in the FRET experiments. Then, using the appropriate calibration curves, together with the CFP and YFP images, the amount of CFP bleed through and YFP cross excitation was calculated for each pixel in the experimental FRET images. These nonFRET components were subtracted from the raw FRET images, yielding corrected FRET images.

\section{FRET efficiency calculation}

The FRET efficiency (FRETeff) was calculated on a pixel-by-pixel basis using the following equation: FRETeff = FRETcorr/(FRETcorr + CFP) X 100\%, where FRETcorr is the pixel intensity in the corrected FRET image, and CFP is the intensity of the corresponding pixel in the CFP channel image.

To increase the reliability of the calculations and to prevent low-level noise from distorting the calculated ratio, we excluded pixels below 50 intensity units and saturated pixels from the calculations and set their intensities to zero. These pixels are shown in black in the "pseudocolored" FRET efficiency images.

To estimate the significance of the FRET efficiency values obtained, and to exclude the possibility of false-positive FRET results, we prepared cells expressing free CFP and free YFP as negative controls. The FRET efficiency in the negative-control system was measured and calculated in the same way as in the main experiment. FRET efficiency values obtained from the negative-control 
samples were subtracted from the values obtained in the main experiments. Image processing and measurements were performed using IPLab software, version 3.9.

\section{PTP Assay}

SHP-1 catalytic activity was determined by measuring the hydrolysis of the exogenous substrate p-Nitrophenyl Phosphate (pNPP) by SHP-1, as previously described(Lorenz, 2011; Matalon, 2018). NK cells $\left(2-5 \times 10^{6}\right)$ were incubated with target cells at ratio of $1: 1$ at $37^{\circ} \mathrm{C}$ for 5 min before lysis. Cells were lysed with ice-cold passive lysis buffer (1.25\% Brij, 0.625\% n-Octyl-b-Dglucoside, $31.3 \mathrm{mM}$ Tris- $\mathrm{HCl}, \mathrm{pH} 7.4,150 \mathrm{mM} \mathrm{NaCl}, 6.25 \mathrm{mM}$ ethylenediaminetetraacetic acid, and complete protease inhibitor tablets (Roche)). Cell lysates were subjected to IP with anti-SHP1 antibody. Immunoprecipitates were washed twice with ice-cold passive washing buffer $(0.1 \%$ Brij, $50 \mathrm{mM}$ Tris- $\mathrm{HCl}, \mathrm{pH}$ 7.4, 300mM NaCl, and 3.75mM ethylenediaminetetraacetic acid), and three times with phosphatase buffer $(150 \mathrm{mM} \mathrm{NaCl}, \quad 50 \mathrm{mM}$ HEPES, 10mM ethylenediaminetetraacetic acid and 1mM DDT). Immunoprecipitates were resuspended in $200 \mu 1$ $25 \mathrm{mM}$ pNPP in phosphatase buffer, and incubated for $30 \mathrm{~min}$ at $37^{\circ} \mathrm{C}$. Reactions were terminated by adding $800 \mu \mathrm{l} 1 \mathrm{M} \mathrm{NaOH}$, and SHP-1 activity was determined by measuring absorbance at $405 \mathrm{~nm}$.

\section{Cytotoxicity assay}

The cytolytic activity of NK cells against target cells was determined with a standard $\left[{ }^{35}\right.$ S $]$ Met release assay. Target cells were labeled with $\left[{ }^{35} \mathrm{~S}\right] \mathrm{Met}(0.2 \mathrm{mCi} / \mathrm{ml})$ for 12 to 16 hours and washed two times, and then $5 \times 10^{3}$ cells were mixed with NK cells at an effector-to-target ratio of 10:1. Cells were then incubated for 5 hours at $37^{\circ} \mathrm{C}$ in complete medium. The cells were centrifuged at $200 \mathrm{~g}$ for $5 \mathrm{~min}$, the supernatant was mixed with scintillation liquid, and radioactive signal was measured with a $\beta$ counter (Packard). Spontaneous release of $\left[{ }^{35} \mathrm{~S}\right] \mathrm{Met}$ from an equal number of 
target cells was determined by adding $100 \mathrm{ml}$ of complete medium to target cells that were incubated without NK cells. Maximal release was determined by adding $100 \mathrm{ml}$ of $0.1 \mathrm{M} \mathrm{NaOH}$ to an equal number of target cells in the absence of NK cells. Finally, the percentage cell lysis caused by the NK cells was calculated using the following equation: $\%$ specific lysis $=[($ sample signal - spontaneous release $) /($ maximal release - spontaneous release $)] \times 100$.

\section{DNA Constructs and Mutagenesis}

Human SHP-1 wt cDNA was obtained from Addgene. The cDNA of SHP-1 was subcloned into the expression vector pEYFP-N1(Clontech) to obtain the chimeric protein YFP-SHP-1; pECFPN1 (Clontech) was subcloned into the YFP-SHP-1 expression vector to obtain the chimeric protein YFP-SHP-1-CFP. To avoid localization of SHP-1 to the nucleus, YFP-SHP1-CFP was mutated at its NLS sequence(He et al., 2005). Molecular mutants were prepared using the QuikChange II XL site-directed mutagenesis kit (Stratagene). The mCherry plasmid was previously described(Pauker, 2012).

\section{Cell transfection and FACS analysis}

YTS-2DL1 or 721.221/K562 cells were transfected with Nucleofector 2b (Lonza) using Amaxa solution R and protocol X-001. Transiently transfected cells were used after 24-48 hrs. Cells transiently expressing chimeric proteins were selected in hygromycin. Fluorescence analysis and cell sorting were performed using FACSAria or FACSVantage (Becton Dickinson Biosciences).

\section{Cell stimulation, immunoblotting and immunoprecipitation}

First, NK cells (primary or YTS cell line) and 721.221 target cells (either expressing HLA-Cw4,

Cw7 or no HLA) were incubated separately on ice for $10 \mathrm{~min}$, at a ratio of $1: 1$. The cells were 
mixed, centrifuged and incubated on ice for $15 \mathrm{~min}$. The cell mixture was then transferred to

$37^{\circ} \mathrm{C}$ for the indicated period of time, and subsequently lysed with ice-cold lysis buffer (1\% Brij,

1\%n-Octyl-b-D-glucoside, 50 mM Tris-HCl, pH 7.6, 150 mM NaCl, 5 mM

ethylenediaminetetraacetic acid, $1 \mathrm{mM} \mathrm{Na}_{3} \mathrm{VO}_{4}$, and complete protease inhibitor tablets). YTS-

2DL1 cells were incubated for $30 \mathrm{~min}$ on ice with the indicated concentration of pervanadate, before and at the time of NK-target cell co-culture.

For analysis of whole cell lysates (WCL), 1-5 x 10 $10^{5}$ cells were used, and for IP experiments 10$15 \times 10^{6}$ cells were used. Protein A/G plus-Agarose beads (Santa Cruz Biotechnology) were used for IP. Protein samples were resolved with sodium dodecyl sulfate-polyacrylamide gel electrophoresis (SDS-PAGE), transferred to nitrocellulose membrane, and immunoblotted with the appropriate primary antibodies. Immunoreactive proteins were detected with either anti-mouse or anti-rabbit horseradish peroxidase-coupled secondary antibody followed by detection with enhanced chemiluminescence (PerkinElmer).

For WCL samples, the phosphorylation or expression level of proteins was measured by densitometric analysis relative to the GAPDH loading control, using ImageJ. For IP samples, the relative binding or phosphorylation level was measured by densitometric analysis relative to the precipitation control, using ImageJ.

\section{Measurement of intracellular calcium concentration}

First, $0.5-1 \times 10^{6} \mathrm{NK}$ cells were incubated with $5 \mu \mathrm{M}$ Indo-1-acetoxymethylester (Indo-1-AM, Teflabs) and $0.5 \mathrm{mM}$ probenecid (MPB) in RPMI 1640 medium at $37^{\circ} \mathrm{C}$ for $45 \mathrm{~min}$. The cells were washed once, resuspended in RPMI 1640 without phenol red containing 10mM HEPES and $0.5 \mathrm{mM}$ probenecid, and maintained at room temperature for $20 \mathrm{~min}$. The cells were incubated at 
$37^{\circ} \mathrm{C}$ for 5 min before measurements, then mixed 1:1 with 721 target cells, and the $\mathrm{Ca}^{2+}$ influx was measured by spectrofluorimetry using the Synergy 4 Microplate Reader (Bio Tek).

\section{CD107a degranulation assay}

NK cells $\left(3 \times 10^{5}\right)$ were co-incubated with $6 \times 10^{5}$ target cells expressing mCherry at $37^{\circ} \mathrm{C}$ for 2 hours in the presence of $2 \mu \mathrm{M}$ monensin (BioLegend). The cells were centrifuged, incubated with 1:1000 diluted anti-CD107a for 30 minutes on ice and washed twice. Cells were then stained with isotype-specific AlexaFluor-conjugated antibody on ice for 30 minutes. Cells were washed twice, and analyzed by FACS. YTS-2DL1 or pNK-2DL1 cells were distinguished from the target cells based on mCherry expression by the targets.

\section{Xenograft mice model}

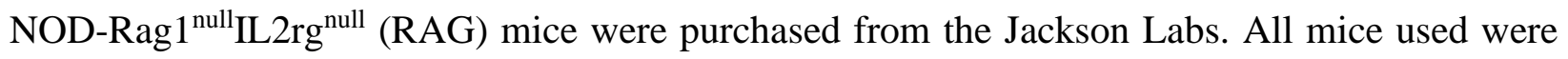
from colonies that were inbred and maintained under SPF conditions at the Bar-Ilan animal house. Housing and breeding of mice and experimental procedures were approved by the Bar-Ilan University Animal Ethics Committee. 6-8 week old female RAG mice were subcutaneously injected, between the shoulders, with $3 \times 10^{6} 721-\mathrm{Cw} 4$ or Cw7 HLA expressing tumor cells, in 0.1 ml of PBS and Matrigel (CORNING) (1:1 ratio). Mice were inspected daily for general well-being, and at the first indication of morbidity (weight loss, lethargy, ruffled fur), or when they reached 8 weeks following inoculation, they were euthanized by $\mathrm{CO}_{2}$. Mice tumor diameters were measured daily with a digital caliper. Tumor volumes were calculated according to the formula:

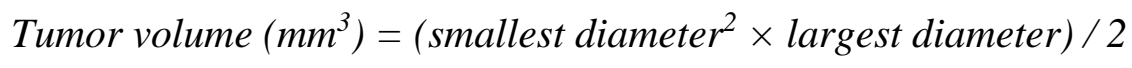


When the tumor volumes reached $75 \mathrm{~mm}^{3}$, mice were intratumorally administered either $3^{*} 10^{6}$ irradiated W.T YTS-2DL1 or SHP-1 deficient NK cells that were untreated or treated with PKC- $\theta$ siRNA. Intratumor injections of NK cells were repeated every 3 days for 6 injections in total.

Average growth rates of the tumor from initiation of treatment were calculated according to the formula:

Average growth rate $=($ Days of treatment $) /($ Last day tumor size - Initial tumor size $)$

\section{Statistical analyses}

Data calculations of Mean \pm SE were conducted in Microsoft Excel (v14.7.2), while data were graphed and statistical analysis was performed using GraphPad Prism 9.0.1 (GraphPad Software, Inc., USA). P values were calculated using a two-tailed unpaired T test or One sample t-test. Where $>2$ conditions were compared, a one-way ANOVA or two way ANOVA with a Tukey post-test was used to calculate P values. Data are depicted as columns with SE. Statistical parameters and biological replicates are reported in the figure legends.

\section{Data availability}

All data generated or analysed during this study are included in the manuscript and supporting file; Source Data files have been provided for Figures 2, 3,5,6,7,8 and supplement figures 1A, 2A and $3 \mathrm{~A}$.

\section{Acknowledgments}

The authors thank Danielle Keizer and Dr. Itay Lazar from Bar-Ilan University for their technical assistance. We thank Dr. Jennifer Benichou Israel Cohen for her help with the statistical analysis. This research was partially funded by the Israel Science Foundation.

\section{Author contributions}

MBS, ABS and BS designed the research. ABS, BS, GB, AP, ML, TJ, NJ, OM and JK performed the experiments. ABS, BS, GB, and MBS analyzed the data. MBS and ABS wrote the paper. 
bioRxiv preprint doi: https://doi.org/10.1101/2021.09.06.459131; this version posted September 6, 2021. The copyright holder for this preprint (which was not certified by peer review) is the author/funder, who has granted bioRxiv a license to display the preprint in perpetuity. It is made available under aCC-BY 4.0 International license.

\section{Conflict of interest}

The authors declare that they have no conflict of interest. 


\section{References}

Aguiló, J. I., Garaude, J., Pardo, J., Villalba, M. and Anel, A. (2009) "Protein kinase C-theta is required for NK cell activation and in vivo control of tumor progression.," Journal of immunology (Baltimore, Md. : 1950), 182(4), pp. 1972-1981. doi: 10.4049/jimmunol.0801820.

Ahern, D. J. and Brennan, F. M. (2011) "The role of Natural Killer cells in the pathogenesis of rheumatoid arthritis: Major contributors or essential homeostatic modulators?," Immunology Letters, 136(2), pp. 115-121. doi: 10.1016/j.imlet.2010.11.001.

André, P., Castriconi, R., Espéli, M., Anfossi, N., Juarez, T., Hue, S., Conway, H., Romagné, F., Dondero, A., Nanni, M., et al. (2004) "Comparative analysis of human NK cell activation induced by NKG2D and natural cytotoxicity receptors," European Journal of Immunology, 34(4), pp. 961-971. doi: 10.1002/eji.200324705.

Andzelm, M. M., Chen, X., Krzewski, K., Orange, J. S. and Strominger, J. L. (2007) "Myosin IIA is required for cytolytic granule exocytosis in human NK cells," 204(10). doi: 10.1084/jem.20071143.

Anel, A., Aguiló, Juan I, Catalán, E., Garaude, J., Rathore, M. G., Pardo, J. and Villalba, M. (2012) "Protein Kinase C- $\theta$ (PKC- $\theta$ ) in Natural Killer Cell Function and Anti-Tumor Immunity.," Frontiers in immunology, 3, p. 187. doi: 10.3389/fimmu.2012.00187.

Anel, A., Aguiló, Juan I., Catalán, E., Garaude, J., Rathore, M. G., Pardo, J. and Villalba, M. (2012) "Protein Kinase C- $\theta$ (PKC- $\theta$ ) in Natural Killer Cell Function and Anti-Tumor Immunity.," Frontiers in immunology, 3(JUL), p. 187. doi: 10.3389/fimmu.2012.00187.

Baier, G., Telford, D., Giampa, L., Coggeshall, K. M., Baier-Bitterlich, G., Isakov, N. and Altman, a (1993) "Molecular cloning and characterization of PKC theta, a novel member of the protein kinase C (PKC) gene family expressed predominantly in hematopoietic cells.," The Journal of biological chemistry, 268(7), pp. 4997-5004. Available at: http://www.ncbi.nlm.nih.gov/pubmed/8444877.

Barda-Saad, M., Braiman, A., Titerence, R., Bunnell, S. C., Barr, V. a and Samelson, L. E. (2005) "Dynamic molecular interactions linking the $\mathrm{T}$ cell antigen receptor to the actin cytoskeleton.," Nature immunology, 6(1), pp. 80-9. doi: 10.1038/ni1143.

Ben-Shmuel, A., Biber, G., Sabag, B. and Barda-Saad, M. (2020) "Modulation of the intracellular inhibitory checkpoint SHP-1 enhances the antitumor activity of engineered NK cells," Cellular \& Molecular Immunology 2020. Nature Publishing Group, pp. 1-3. doi: 10.1038/s41423-020-0443-6.

Brumell, J. H., Chan, C. K., Butler, J., Borregaard, N., Siminovitch, K. a., Grinstein, S. and Downey, G. P. (1997) "Regulation of Src Homology 2-containing Tyrosine Phosphatase 1 during Activation of Human Neutrophils: ROLE OF PROTEIN KINASE C," Journal of Biological Chemistry, 272(2), pp. 875-882. doi: 10.1074/jbc.272.2.875.

Bryceson, Y. T., March, M. E., Ljunggren, H.-G. and Long, E. O. (2006) "Synergy among receptors on resting NK cells for the activation of natural cytotoxicity and cytokine secretion.," Blood, 107(1), pp. 159-66. doi: 10.1182/blood-2005-04-1351.

Burroughs, N. J. and Wülfing, C. (2002) "Differential segregation in a cell-cell contact interface: the dynamics of the immunological synapse.," Biophysical journal, 83(4), pp. 1784-1796. doi: 


\subsection{6/S0006-3495(02)73944-1.}

Caraux, A., Kim, N., Bell, S. E., Zompi, S., Ranson, T., Lesjean-Pottier, S., Garcia-Ojeda, M. E., Turner, M. and Colucci, F. (2006) "Phospholipase C-gamma2 is essential for NK cell cytotoxicity and innate immunity to malignant and virally infected cells.," Blood, 107(3), pp. 994-1002. doi: 10.1182/blood-2005-06-2428.

Carisey, A. F., Mace, E. M., Saeed, M. B., Davis, D. M. and Orange, J. S. (2018) "Nanoscale Dynamism of Actin Enables Secretory Function in Cytolytic Cells," Current Biology, 28(4), pp. 489-502.e9. doi: 10.1016/j.cub.2017.12.044.

Carretero, M., Palmieri, G., Llano, M., Tullio, V., Santoni, A., Geraghty, D. E. and López-Botet, M. (1998) "Specific engagement of the CD94/NKG2-A killer inhibitory receptor by the HLA-E class Ib molecule induces SHP-1 phosphatase recruitment to tyrosine-phosphorylated NKG2-A: Evidence for receptor function in heterologous transfectants," European Journal of Immunology, 28(4), pp. 1280-1291. doi: 10.1002/(SICI)1521-4141(199804)28:04<1280::AID-

IMMU1280>3.0.CO;2-O.

Chand, S., Mehta, N., Singh Bahia, M., Dixit, A. and Silakari, O. (2012) "Protein Kinase C-theta Inhibitors: A Novel Therapy for Inflammatory Disorders," Current Pharmaceutical Design, 18(30), pp. 4725-4746. doi: 10.2174/138161212802651625.

Chemnitz, J. M., Parry, R. V, Nichols, K. E., June, C. H. and Riley, J. L. (2004) "SHP-1 and SHP-2 associate with immunoreceptor tyrosine-based switch motif of programmed death 1 upon primary human $\mathrm{T}$ cell stimulation, but only receptor ligation prevents T cell activation.," Journal of immunology (Baltimore, Md. : 1950), 173(2), pp. 945-54. doi: 10.4049/jimmunol.173.2.945.

Choi, P. J. and Mitchison, T. J. (2013) "Imaging burst kinetics and spatial coordination during serial killing by single natural killer cells.," Proceedings of the National Academy of Sciences of the United States of America, 110(16), pp. 6488-6493. doi: 10.1073/pnas.1221312110.

Curnock, A., Bolton, C., Chiu, P., Doyle, E., Fraysse, D., Hesse, M., Jones, J., Weber, P. and Jimenez, J. M. (2014) "Selective protein kinase C $\theta$ (PKC $\theta$ ) inhibitors for the treatment of autoimmune diseases," Biochemical Society Transactions, 42(6), pp. 1524-1528. doi: 10.1042/BST20140167.

Das, J. (2010) "Activation or tolerance of natural killer cells is modulated by ligand quality in a nonmonotonic manner.," Biophysical journal. The Biophysical Society, 99(7), pp. 2028-2037. doi: 10.1016/j.bpj.2010.07.061.

Dong, Z., Davidson, D., Pérez-Quintero, L. A., Kurosaki, T., Swat, W. and Veillette, A. (2012) "The Adaptor SAP Controls NK Cell Activation by Regulating the Enzymes Vav-1 and SHIP-1 and by Enhancing Conjugates with Target Cells," Immunity, 36(6), pp. 974-985. doi:

10.1016/j.immuni.2012.03.023.

Dotta, F., Censini, S., van Halteren, A. G. S., Marselli, L., Masini, M., Dionisi, S., Mosca, F., Boggi, U., Muda, A. O., Del Prato, S., et al. (2007) "Coxsackie B4 virus infection of beta cells and natural killer cell insulitis in recent-onset type 1 diabetic patients.," Proceedings of the National Academy of Sciences of the United States of America. National Academy of Sciences, 104(12), pp. 5115-20. doi: 10.1073/pnas.0700442104.

Egelhoff, T. T., Lee, R. J. and Spudich, J. A. (1993) "Dictyostelium myosin heavy chain phosphorylation sites regulate myosin filament assembly and localization in vivo," Cell. Cell 
Press, 75(2), pp. 363-371. doi: 10.1016/0092-8674(93)80077-R.

Feng, J., Garrity, D., Call, M. E., Moffett, H. and Wucherpfennig, K. W. (2005) "Convergence on a distinctive assembly mechanism by unrelated families of activating immune receptors.," Immunity, 22(4), pp. 427-38. doi: 10.1016/j.immuni.2005.02.005.

Forslund, E., Sohlberg, E., Enqvist, M., Olofsson, P. E., Malmberg, K.-J. and Önfelt, B. (2015) "Microchip-Based Single-Cell Imaging Reveals That CD56 dim CD57 - KIR ${ }^{-}$NKG2A + NK Cells Have More Dynamic Migration Associated with Increased Target Cell Conjugation and Probability of Killing Compared to CD56 <," The Journal of Immunology, 195(7), pp. 33743381. doi: 10.4049/jimmunol.1500171.

Fried, S., Reicher, B., Pauker, M. H., Eliyahu, S., Matalon, O., Noy, E., Chill, J. and Barda-Saad, M. (2014) "Triple-color FRET analysis reveals conformational changes in the WIP-WASp actinregulating complex.," Science signaling, 7(331), p. ra60. doi: 10.1126/scisignal.2005198.

Guldevall, K., Brandt, L., Forslund, E., Olofsson, K., Frisk, T. W., Olofsson, P. E., Gustafsson, K., Manneberg, O., Vanherberghen, B., Brismar, H., et al. (2016) "Microchip Screening Platform for Single Cell Assessment of NK Cell Cytotoxicity," Frontiers in Immunology, 7, p. 119. doi: 10.3389/fimmu.2016.00119.

Hayashi, K. and Altman, A. (2007) "Protein kinase C theta (PKCtheta): a key player in T cell life and death.," Pharmacological research : the official journal of the Italian Pharmacological Society, 55(6), pp. 537-544. doi: 10.1016/j.phrs.2007.04.009.

He, D., Song, X., Liu, L., Burk, D. H. and Zhou, G. W. (2005) "EGF-stimulation activates the nuclear localization signal of SHP-1," Journal of Cellular Biochemistry, 94(5), pp. 944-953. doi: 10.1002/jcb.20307.

Hsu, H. T., Mace, E. M., Carisey, A. F., Viswanath, D. I., Christakou, A. E., Wiklund, M., Önfelt, B. and Orange, J. S. (2016) "NK cells converge lytic granules to promote cytotoxicity and prevent bystander killing," Journal of Cell Biology, 215(6). doi: 10.1083/jcb.201604136.

Huang, R.-Y., Eppolito, C., Lele, S., Shrikant, P., Matsuzaki, J. and Odunsi, K. (2015) "LAG3 and PD1 co-inhibitory molecules collaborate to limit CD8+ T cell signaling and dampen antitumor immunity in a murine ovarian cancer model.," Oncotarget. Impact Journals, LLC, 6(29), pp. 27359-27377. doi: 10.18632/oncotarget.4751.

Huang, W. and Erikson, R. L. (1994) "Constitutive activation of Mek1 by mutation of serine phosphorylation sites.," Proceedings of the National Academy of Sciences of the United States of America. National Academy of Sciences, 91(19), pp. 8960-8963. doi:

10.1073/PNAS.91.19.8960.

Jochems, C., Hodge, J. W., Fantini, M., Fujii, R., Morillon, Y. M., Greiner, J. W., Padget, M. R., Tritsch, S. R., Tsang, K. Y., Campbell, K. S., et al. (2016) "An NK cell line (haNK) expressing high levels of granzyme and engineered to express the high affinity CD16 allele.," Oncotarget. Oncotarget, 7(52), pp. 86359-86373. doi: 10.18632/oncotarget.13411.

Jones, M. L., Craik, J. D., Gibbins, J. M. and Poole, A. W. (2004) "Regulation of SHP-1 tyrosine phosphatase in human platelets by serine phosphorylation at its $\mathrm{C}$ terminus.," The Journal of biological chemistry, 279(39), pp. 40475-40483. doi: 10.1074/jbc.M402970200.

Kim, H. S., Das, A., Gross, C. C., Bryceson, Y. T. and Long, E. O. (2010) "Synergistic signals for natural cytotoxicity are required to overcome inhibition by c-Cbl ubiquitin ligase.," 
Immunity, 32(2), pp. 175-86. doi: 10.1016/j.immuni.2010.02.004.

Krzewski, K., Chen, X., Orange, J. S. and Strominger, J. L. (2006) "Formation of a WIP-, WASp-, actin-, and myosin IIA-containing multiprotein complex in activated NK cells and its alteration by KIR inhibitory signaling.," The Journal of cell biology, 173(1), pp. 121-132. doi: $10.1083 /$ jcb.200509076.

Lanier, L. L. (2003) "Natural killer cell receptor signaling," pp. 308-314. doi: 10.1016/S09527915(03)00039-6.

Lanier, L. L. (2005) "NK cell recognition.," Annual review of immunology, 23, pp. 225-74. doi: 10.1146/annurev.immunol.23.021704.115526.

Lee, K.-M., Chuang, E., Griffin, M., Khattri, R., Hong, D. K., Zhang, W., Straus, D., Samelson, L. E., Thompson, C. B. and Bluestone, J. A. (1998) "Molecular Basis of T Cell Inactivation by CTLA-4," Science. American Association for the Advancement of Science, 282(5397), pp. 2263-2266. doi: 10.1126/science.282.5397.2263.

Léger, J., Kempf, M., Lee, G. and Brandt, R. (1997) “Conversion of serine to aspartate imitates phosphorylation-induced changes in the structure and function of microtubule-associated protein tau.," The Journal of biological chemistry, 272(13), pp. 8441-8446. Available at: http://www.ncbi.nlm.nih.gov/pubmed/9079670.

Li, R. Y., Gaits, F., Ragab, a, Ragab-Thomas, J. M. and Chap, H. (1995) "Tyrosine phosphorylation of an SH2-containing protein tyrosine phosphatase is coupled to platelet thrombin receptor via a pertussis toxin-sensitive heterotrimeric G-protein.," The EMBO journal, 14(11), pp. 2519-2526. Available at:

http://www.pubmedcentral.nih.gov/articlerender.fcgi?artid=398365\&tool=pmcentrez\&rendertyp $\mathrm{e}=$ abstract.

Liu, Y., Kruhlak, M. J., Hao, J.-J. and Shaw, S. (2007) "Rapid T cell receptor-mediated SHP-1 S591 phosphorylation regulates SHP-1 cellular localization and phosphatase activity.," Journal of leukocyte biology, 82(3), pp. 742-51. doi: 10.1189/jlb.1206736.

Long, E. O. (2008) "Negative signaling by inhibitory receptors: The NK cell paradigm," Immunological Reviews, 224(1), pp. 70-84.

Lorenz, U. (2009) "SHP-1 and SHP-2 in T cells: two phosphatases functioning at many levels.," Immunological reviews, 228(1), pp. 342-359. doi: 10.1111/j.1600-065X.2008.00760.x.

Lorenz, U. (2011) "Protein tyrosine phosphatase assays.," Current protocols in immunology / edited by John E. Coligan ... [et al.], Chapter 11, p. Unit 11.7. doi: 10.1002/0471142735.im1107s93.

Malhotra, A. and Shanker, A. (2011) "NK cells: immune cross-talk and therapeutic implications.," Immunotherapy, 3(10), pp. 1143-66. doi: 10.2217/imt.11.102.

Matalon, O., Ben-Shmuel, A., Kivelevitz, J., Sabag, B., Fried, S., Joseph, N., Noy, E., Biber, G. and Barda-Saad, M. (2018) "Actin retrograde flow controls natural killer cell response by regulating the conformation state of SHP-1.," The EMBO journal, 37(5), p. e96264. doi: 10.15252/embj.201696264.

Matalon, O., Fried, S., Ben-shmuel, A., Pauker, M. H., Joseph, N., Keizer, D., Piterburg, M. and Barda-saad, M. (2016) "Dephosphorylation of the adaptor LAT and phospholipase C - g by SHP-1 inhibits natural killer cell cytotoxicity," 9(429), pp. 1-16. doi: 10.1126/scisignal.aad6182. 
Merino, E., Abeyweera, T. P., Firth, M. A., Zawislak, C. L., Basu, R., Liu, X., Sun, J. C. and Huse, M. (2012) "Protein kinase C- $\theta$ clustering at immunological synapses amplifies effector responses in NK cells.," Journal of immunology (Baltimore, Md. : 1950). American Association of Immunologists, 189(10), pp. 4859-69. doi: 10.4049/jimmunol.1200825.

Mizesko, M. C., Banerjee, P. P., Monaco-Shawver, L., Mace, E. M., Bernal, W. E., SawalleBelohradsky, J., Belohradsky, B. H., Heinz, V., Freeman, A. F., Sullivan, K. E., et al. (2013) "Defective actin accumulation impairs human natural killer cell function in patients with dedicator of cytokinesis 8 deficiency.," The Journal of allergy and clinical immunology. NIH Public Access, 131(3), pp. 840-8. doi: 10.1016/j.jaci.2012.12.1568.

Monks, C. R., Kupfer, H., Tamir, I., Barlow, A. and Kupfer, A. (1997) "Selective modulation of protein kinase C-theta during T-cell activation.," Nature, 385(6611), pp. 83-86. doi: $10.1038 / 385083 \mathrm{a} 0$.

Morandi, B., Bramanti, P., Bonaccorsi, I., Montalto, E., Oliveri, D., Pezzino, G., Navarra, M. and Ferlazzo, G. (2008) "Role of natural killer cells in the pathogenesis and progression of multiple sclerosis," Pharmacological Research, 57(1), pp. 1-5. doi: 10.1016/j.phrs.2007.11.003.

Moretta, L., Ciccone, E., Mingari, M. C., Biassoni, R. and Moretta, A. (1994) "Human natural killer cells: origin, clonality, specificity, and receptors.," Advances in immunology, 55, pp. 341380. Available at: http://www.ncbi.nlm.nih.gov/pubmed/7508176.

Münz, C., Holmes, N., King, A., Loke, Y. W., Colonna, M., Schild, H. and Rammensee, H. G. (1997) "Human histocompatibility leukocyte antigen (HLA)-G molecules inhibit NKAT3 expressing natural killer cells.," The Journal of experimental medicine. The Rockefeller University Press, 185(3), pp. 385-391. Available at: http://www.ncbi.nlm.nih.gov/pubmed/9053439.

Netter, P., Anft, M. and Watzl, C. (2017) "Termination of the Activating NK Cell Immunological Synapse Is an Active and Regulated Process.," Journal of immunology (Baltimore, Md. : 1950), 199(7), pp. 2528-2535. doi: 10.4049/jimmunol.1700394.

Nicolle, A., Zhang, Y. and Belguise, K. (2021) "The emerging function of pkctheta in cancer," Biomolecules, 11(2), pp. 1-12. doi: 10.3390/biom11020221.

Orange, J. S., Ramesh, N., Remold-O’Donnell, E., Sasahara, Y., Koopman, L., Byrne, M., Bonilla, F. A., Rosen, F. S., Geha, R. S. and Strominger, J. L. (2002) "Wiskott-Aldrich syndrome protein is required for NK cell cytotoxicity and colocalizes with actin to NK cell-activating immunologic synapses.," Proceedings of the National Academy of Sciences of the United States of America, 99(17), pp. 11351-6. doi: 10.1073/pnas.162376099.

Orr, M. T. and Lanier, L. L. (2010) "Review Natural Killer Cell Education and Tolerance," Cell. Elsevier Inc., 142(6), pp. 847-856. doi: 10.1016/j.cell.2010.08.031.

Osada, S., Mizuno, K., Saido, T. C., Suzuki, K., Kuroki, T. and Ohno, S. (1992) "A new member of the protein kinase $\mathrm{C}$ family, $\mathrm{nPKC}$ theta, predominantly expressed in skeletal muscle.," Molecular and Cellular Biology, 12(9), pp. 3930-3938. doi: 10.1128/MCB.12.9.3930.

Page, K. M., Chaudhary, D., Goldman, S. J. and Kasaian, M. T. (2008) "Natural killer cells from protein kinase $\mathrm{C}$ theta-/- mice stimulated with interleukin-12 are deficient in production of interferon-gamma.," Journal of leukocyte biology, 83(5), pp. 1267-1276. doi: 10.1189/jlb.1107745. 
Pauker, M. H., Hassan, N., Noy, E., Reicher, B. and Barda-Saad, M. (2012) "Studying the dynamics of SLP-76, Nck, and Vav1 multimolecular complex formation in live human cells with triple-color FRET.," Science signaling, 5(221), p. rs3. doi: 10.1126/scisignal.2002423.

Pipkin, M. E. and Lieberman, J. (no date) "Delivering the kiss of death : progress on understanding how perforin works." doi: 10.1016/j.coi.2007.04.011.

Poole, A. W. and Jones, M. L. (2005) "A SHPing tale: perspectives on the regulation of SHP-1 and SHP-2 tyrosine phosphatases by the C-terminal tail.," Cellular signalling, 17(11), pp. 132332. doi: 10.1016/j.cellsig.2005.05.016.

Purdy, A. K. and Campbell, K. S. (2009) "SHP-2 expression negatively regulates NK cell function.," Journal of immunology (Baltimore, Md. : 1950). NIH Public Access, 183(11), pp. 7234-43. doi: 10.4049/jimmunol.0900088.

Ran, F. A., Hsu, P. D., Wright, J., Agarwala, V., Scott, D. A. and Zhang, F. (2013) "Genome engineering using the CRISPR-Cas9 system.," Nature protocols. Nature Publishing Group, a division of Macmillan Publishers Limited. All Rights Reserved., 8(11), pp. 2281-2308. doi: 10.1038/nprot.2013.143.

Sheppard, K.-A., Fitz, L. J., Lee, J. M., Benander, C., George, J. A., Wooters, J., Qiu, Y., Jussif, J. M., Carter, L. L., Wood, C. R., et al. (2004) "PD-1 inhibits T-cell receptor induced phosphorylation of the ZAP70/CD3 $\zeta$ signalosome and downstream signaling to PKC $\theta$," FEBS Letters, 574(1-3), pp. 37-41. doi: 10.1016/j.febslet.2004.07.083.

Siegler, E. L., Kim, Y. J., Chen, X., Siriwon, N., Mac, J., Rohrs, J. A., Bryson, P. D. and Wang, P. (2017) "Combination Cancer Therapy Using Chimeric Antigen Receptor-Engineered Natural Killer Cells as Drug Carriers,” Molecular Therapy. doi: 10.1016/j.ymthe.2017.08.010.

Srpan, K., Ambrose, A., Karampatzakis, A., Saeed, M., Cartwright, A. N. R., Guldevall, K., De Matos, G. D. S. C., Önfelt, B. and Davis, D. M. (2018) "Shedding of CD16 disassembles the NK cell immune synapse and boosts serial engagement of target cells," Journal of Cell Biology, 217(9). doi: 10.1083/jcb.201712085.

Stebbins, C. C., Watzl, C., Billadeau, D. D., Leibson, P. J., Burshtyn, D. N. and Long, E. O. (2003) "Vav1 Dephosphorylation by the Tyrosine Phosphatase SHP-1 as a Mechanism for Inhibition of Cellular Cytotoxicity," Molecular and Cellular Biology, 23(17), pp. 6291-6299. doi: 10.1128/MCB.23.17.6291-6299.2003.

Tassi, I., Cella, M., Presti, R., Colucci, A., Gilfillan, S., Littman, D. R. and Colonna, M. (2008) "NK cell-activating receptors require PKC-theta for sustained signaling, transcriptional activation, and IFN-gamma secretion.," Blood, 112(10), pp. 4109-4116. doi: 10.1182/blood2008-02-139527.

Topham, N. J. and Hewitt, W. (2009) "Natural killer cell cytotoxicity : how do they pull the trigger ?,” pp. 7-15. doi: 10.1111/j.1365-2567.2009.03123.x.

Upshaw, J. L., Arneson, L. N., Schoon, R. a, Dick, C. J., Billadeau, D. D. and Leibson, P. J. (2006) "NKG2D-mediated signaling requires a DAP10-bound Grb2-Vav1 intermediate and phosphatidylinositol-3-kinase in human natural killer cells.," Nature immunology, 7(5), pp. 52432. doi: 10.1038/ni1325.

Viant, C., Fenis, A., Chicanne, G., Payrastre, B., Ugolini, S. and Vivier, E. (2014) "SHP-1mediated inhibitory signals promote responsiveness and anti-tumour functions of natural killer 
cells.," Nature communications, 5, p. 5108. doi: 10.1038/ncomms6108.

Vyas, Y. M., Maniar, H. and Dupont, B. (2002a) "Cutting edge: differential segregation of the SRC homology 2-containing protein tyrosine phosphatase-1 within the early NK cell immune synapse distinguishes noncytolytic from cytolytic interactions.," Journal of immunology (Baltimore, Md. : 1950), 168(7), pp. 3150-4.

Vyas, Y. M., Maniar, H. and Dupont, B. (2002b) "Visualization of signaling pathways and cortical cytoskeleton in cytolytic and noncytolytic natural killer cell immune synapses.,"

Immunological reviews, 189, pp. 161-178. Available at:

http://www.ncbi.nlm.nih.gov/pubmed/12445273.

Vyas, Y. M., Mehta, K. M., Morgan, M., Maniar, H., Butros, L., Jung, S., Burkhardt, J. K. and Dupont, B. (2001) "Spatial organization of signal transduction molecules in the NK cell immune synapses during MHC class I-regulated noncytolytic and cytolytic interactions.," Journal of immunology (Baltimore, Md. : 1950), 167(8), pp. 4358-67.

Wagtmann, N., Rajagopalan, S., Winter, C. C., Peruui, M. and Long, E. O. (1995) "Killer cell inhibitory receptors specific for HLA-C and HLA-B identified by direct binding and by functional transfer," Immunity. Elsevier, 3(6), pp. 801-809. doi: 10.1016/1074-7613(95)90069-1.

Wang, W., Liu, L., Song, X., Mo, Y., Komma, C., Bellamy, H. D., Zhao, Z. J. and Zhou, G. W. (2011) "Crystal structure of human protein tyrosine phosphatase SHP-1 in the open conformation," Journal of Cellular Biochemistry, 112(8), pp. 2062-2071. doi:

$10.1002 /$ jcb. 23125 .

Wang, X. D., Gong, Y., Chen, Z. L., Gong, B. N., Xie, J. J., Zhong, C. Q., Wang, Q. L., Diao, L. H., Xu, A., Han, J., et al. (2015) "TCR-induced sumoylation of the kinase PKC-\$ $\theta \$$ controls T cell synapse organization and T cell activation," Nature Immunology, 16(11), pp. 1195-1203. doi: 10.1038/ni.3259.

Watanabe, N., Gavrieli, M., Sedy, J. R., Yang, J., Fallarino, F., Loftin, S. K., Hurchla, M. A., Zimmerman, N., Sim, J., Zang, X., et al. (2003) "BTLA is a lymphocyte inhibitory receptor with similarities to CTLA-4 and PD-1," Nature Immunology, 4(7), pp. 670-679. doi: 10.1038/ni944.

Wu, C., Guan, Q., Wang, Y., Zhao, Z. J. and Zhou, G. W. (2003) "SHP-1 suppresses cancer cell growth by promoting degradation of JAK kinases.," Journal of cellular biochemistry, 90(5), pp. 1026-1037. doi: 10.1002/jcb.10727.

Zhou, X., Zhao, R., Schwarz, K., Mangeat, M., Schwarz, E. C., Hamed, M., Bogeski, I., Helms, V., Rieger, H. and Qu, B. (2017) "Bystander cells enhance NK cytotoxic efficiency by reducing search time,” Scientific Reports. Nature Publishing Group, 7, p. 44357. doi: 10.1038/srep44357. 


\section{Supplementary figures:}

\section{Fig 1-Fig. supplement 1}

\section{A}

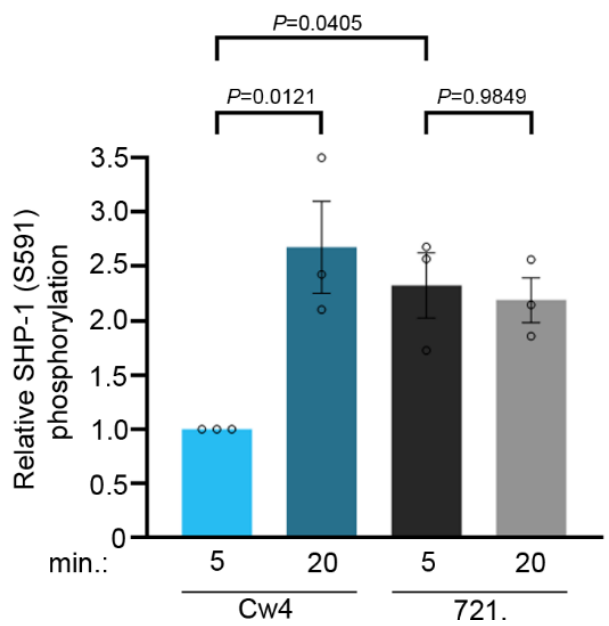

Figure 1-Figure Supplement 1:Phosphorylation of SHP-1 S591 is mediated through PKC- $\boldsymbol{\theta}$. (A) pNK-2DL1 cells were incubated with target cells as described in Fig. 1C, for two different activation time points, as indicated. pSHP-1 S591 levels were determined as in Fig. 1C. pSHP-1 S591 levels of pNK-2DL1 cells incubated with targets for 5 and 20 minutes are shown on the bar graph. The bar graph shows the average of 4 independent experiments. 


\section{Figure 3-Figure supplement 1}

A
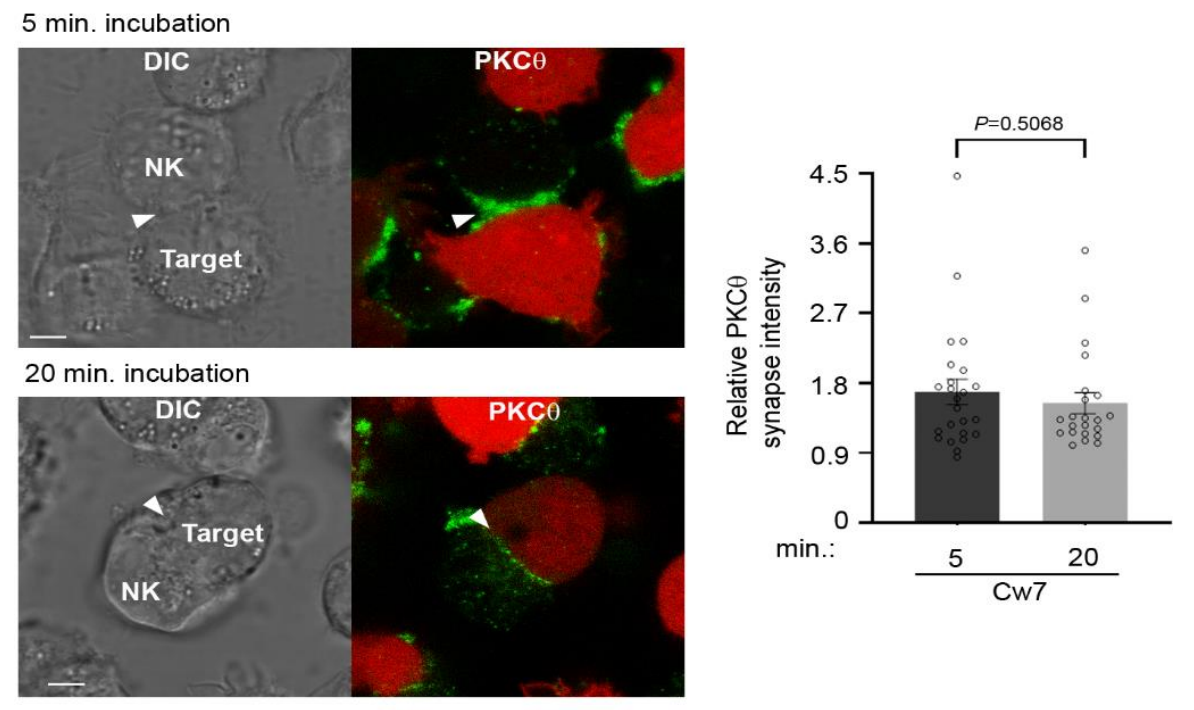

B

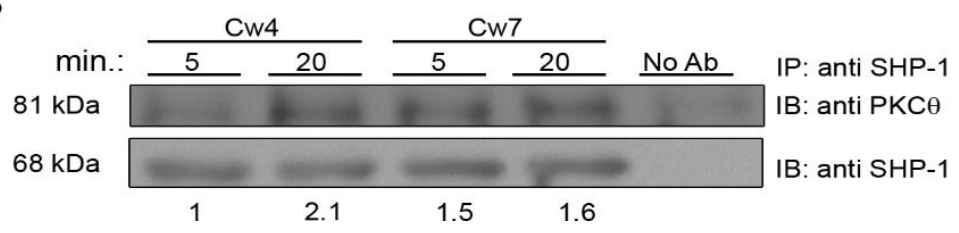

Figure 3-Figure Supplement 1:Phosphorylation of SHP-1 is mediated through PKC.(A) YTS-2DL1 cells were incubated over slides pre-seeded with 721-Cw7 target cells expressing mCherry. The cells were incubated for 5 or 20 minutes at $37^{\circ} \mathrm{C}$ to enable conjugate formation, and were fixed. PKC- $\theta$ was subsequently labeled with primary goat anti PKC- $\theta$ antibody, and secondary anti-goat 488 antibody. Graph summarizing PKC- $\theta$ accumulation at the NKIS during each activation time. Analysis was conducted comparing PKC- $\theta$ intensity at the NKIS relative to the rest of the NK cell. For $\mathrm{Cw} 7,5$ and 20 minute activation, $\mathrm{n}=27$, and 24 conjugates were analyzed. (B) YTS-2DL1 cells were incubated with 721.221 targets for the indicated times. Subsequently, cells were lysed, and lysates were immunoprecipitated with anti-SHP-1 antibody. Lysates were then separated on SDS page and immunoblotted with anti PKC- $\theta$ antibody or anti SHP-1 antibody as a loading control. Densitometry was performed relative to YTS-2DL1 sample vs. 721-Cw4 after 5 min activation. 


\section{Figure 4 -Figure supplement 1}

A
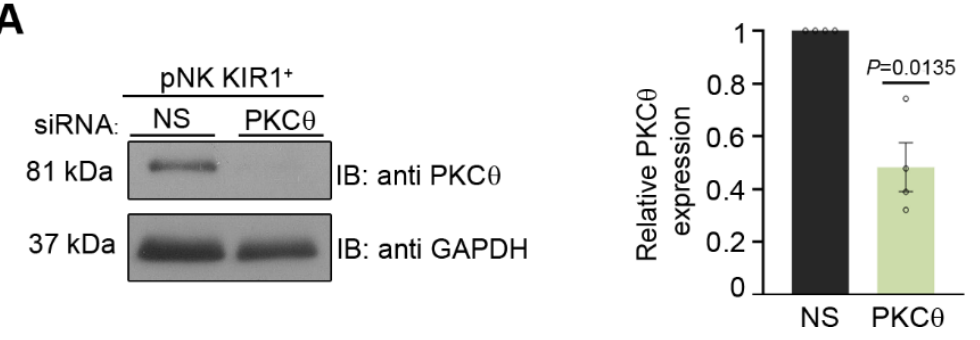

Figure 4-Figure Supplement 1: (A) Silencing efficiency of PKC- $\theta$. pNK-2DL1 cells were transfected with 250 pmol of PKC- $\theta$ siRNA. After 48hrs, prior to incubation with target cells, pNK-2DL1 were counted and lysed. Lysates were separated on SDS page and immunoblotted with anti PKC- $\theta$ antibody. PKC- $\theta$ expression levels were measured by densitometric analysis, relative to the GAPDH loading control using ImageJ. Samples were normalized according to the pNK-N.S siRNA sample. Bar graph on the right shows the average of data pooled from 3 independent experiments. Data are shown as mean \pm SEM. one-way ANOVA with Tukey test (A) or one -sample t test (B, D) were used to calculate $\mathrm{p}$ values.

\section{Figure 5 -Figure supplement 1}

A
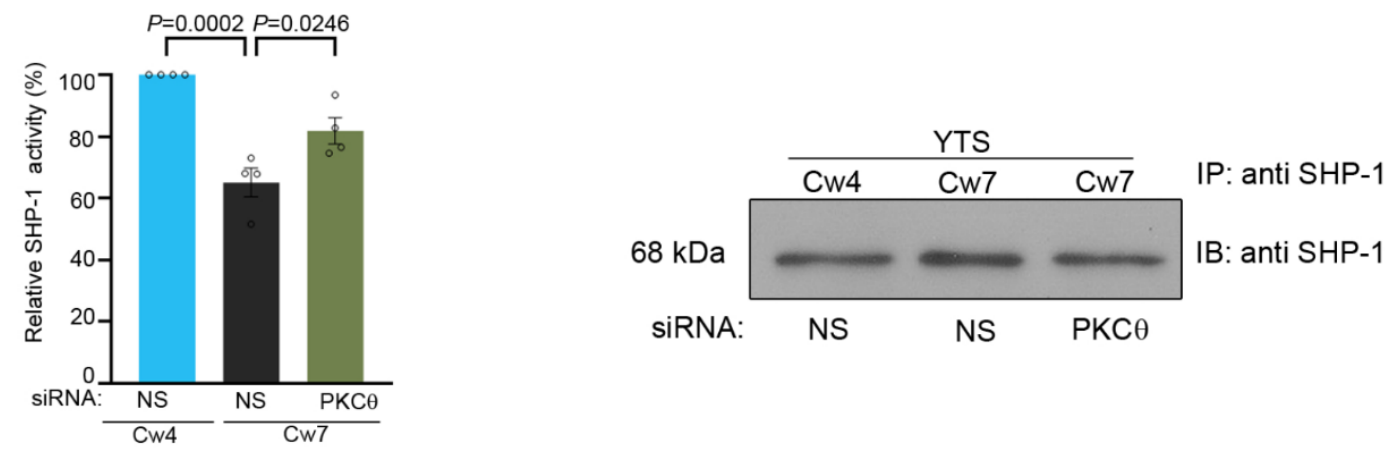

Figure 5-Figure Supplement 1: The role of PKC- $\theta$ in NK cell activation. (A) YTS-2DL1 cells were treated with N.S or PKC- $\theta$ siRNA for 48 hrs, and SHP-1 activity was determined. Loading control of SHP-1 precipitated for the PTP assay is shown to the right. The bar graph represents averages of 4 independent experiments. 


\section{Figure 6 -Figure supplement 1}

\section{A}
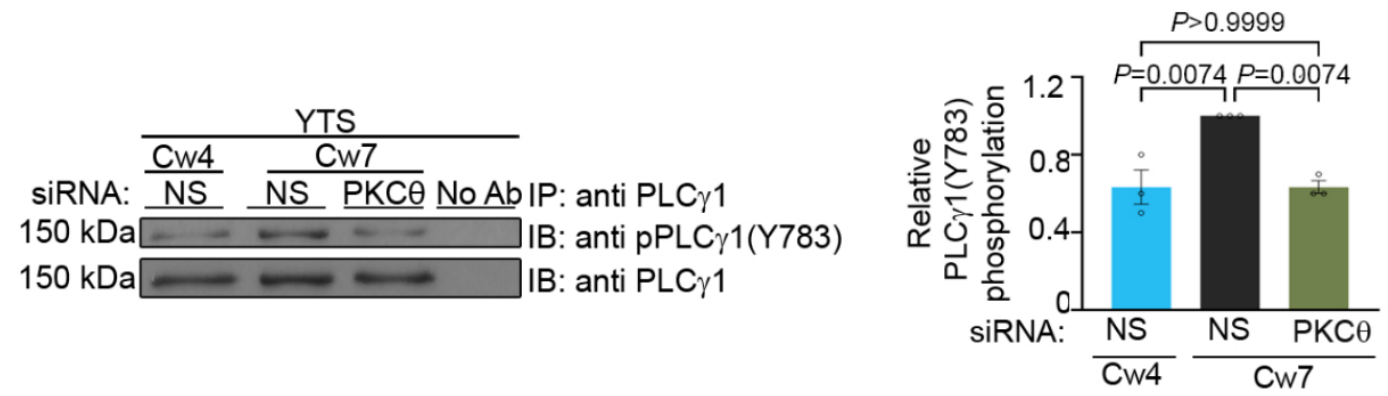

Figure 6 -Figure Supplement 1: (A) YTS-2DL1 cells were transfected with either N.S or PKC- $\theta$ siRNA 48 hrs prior to the experiment. Cells were incubated with either $721-\mathrm{Cw} 4$ or $\mathrm{CW} 7$ target cells for 5 minutes at $37^{\circ} \mathrm{C}$, and subsequently lysed. Lysates were immunoprecipitated on beads containing PLC $\gamma-1$ antibody and immunoblotted for pPLC $\gamma$-1(Y783). Densitometric analysis was normalized to PLC $\gamma$-1 loading controls, and relative to the YTS-2DL1 N.S siRNA: CW7 pPLC $\gamma-1$ (Y783) sample. Bar graph on the right shows the average of data pooled from 3 independent experiments. Data are shown as mean \pm SEM. one-way ANOVA with Tukey test (A, B) were used to calculate $p$ values. 


\section{Figure 7-Figure Supplement 1:}

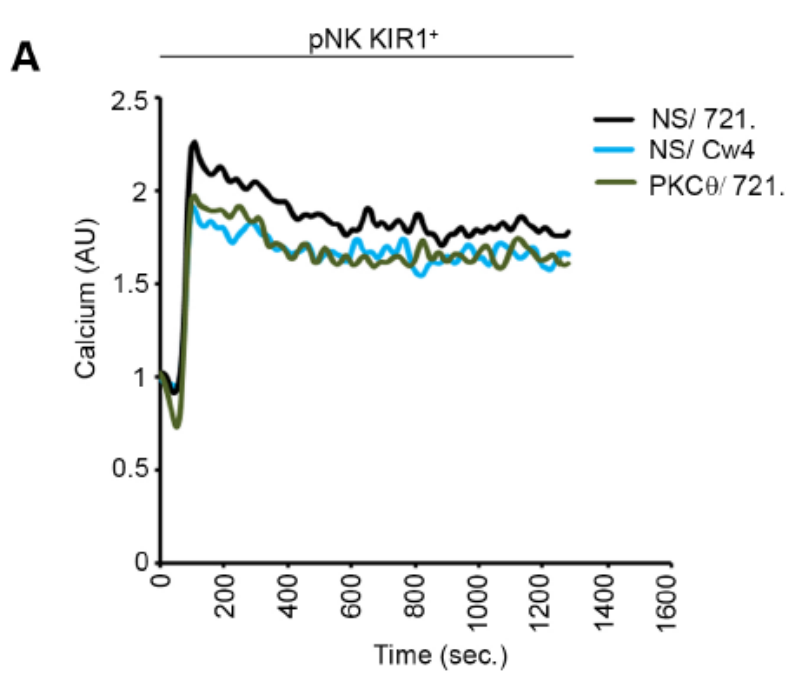

B

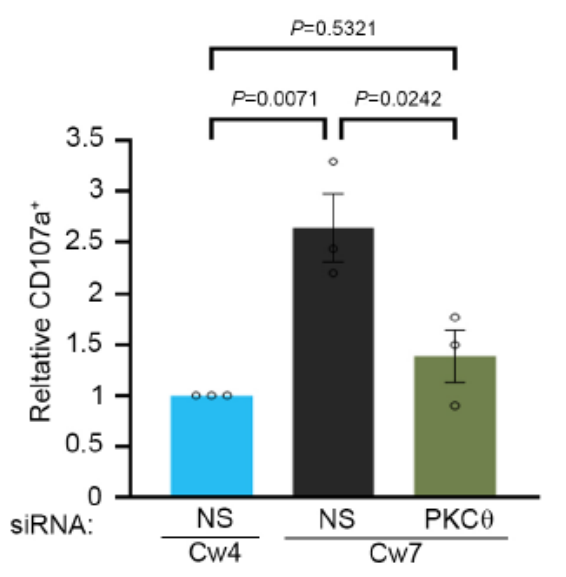

Figure 7-Figure Supplement 1:NK cell activation threshold is increased following gene silencing of PKC- $\theta$. (A) pNK-2DL1 cells were transfected with specific PKC- $\theta$ siRNA or with N.S siRNA, and were used after 48 hrs. pNK-2DL1 cells were loaded with Fluo-3-AM, and analyzed for basal intracellular calcium levels for 1 minute. The NK cells were then mixed with 721-Cw4 or 721-HLA negative target cells, incubated at $37^{\circ} \mathrm{C}$ and analyzed by spectrofluorometry. (B) pNK-2DL1 cells were PKC- $\theta$ gene silenced or treated with non-specific siRNA. pNK-2DL1 cells were incubated with mCherry-expressing $721-\mathrm{Cw} 7$ or $\mathrm{Cw} 4$ target cells for 2 hours at $37^{\circ} \mathrm{C}$ and analyzed for degranulation via FACS. Bar graph on the right is normalized to the pNK-2DL1 vs. Cw4 sample, and represents averages of 3 independent experiments. Data are shown as mean \pm SEM. one-way ANOVA with Tukey test (A, B) were used to calculate $\mathrm{p}$ values. 